\title{
Modeling Global Sea Ice with a Thickness and Enthalpy Distribution Model in Generalized Curvilinear Coordinates
}

\author{
JiNLUN ZHANG AND D. A. Rothrock \\ Polar Science Center, Applied Physics Laboratory, College of Ocean and Fishery Sciences, \\ University of Washington, Seattle, Washington
}

(Manuscript received 30 January 2002, in final form 10 September 2002)

ABSTRACT

\begin{abstract}
A parallel ocean and ice model (POIM) in generalized orthogonal curvilinear coordinates has been developed for global climate studies. The POIM couples the Parallel Ocean Program (POP) with a 12-category thickness and enthalpy distribution (TED) sea ice model. Although the POIM aims at modeling the global ocean and sea ice system, the focus of this study is on the presentation, implementation, and evaluation of the TED sea ice model in a generalized coordinate system. The TED sea ice model is a dynamic thermodynamic model that also explicitly simulates sea ice ridging. Using a viscous plastic rheology, the TED model is formulated such that all the metric terms in generalized curvilinear coordinates are retained. Following the POP's structure for parallel computation, the TED model is designed to be run on a variety of computer architectures: parallel, serial, or vector. When run on a computer cluster with 10 parallel processors, the parallel performance of the POIM is close to that of a corresponding POP ocean-only model. Model results show that the POIM captures the major features of sea ice motion, concentration, extent, and thickness in both polar oceans. The results are in reasonably good agreement with buoy observations of ice motion, satellite observations of ice extent, and submarine observations of ice thickness. The model biases are within $8 \%$ in Arctic ice motion, within 9\% in Arctic ice thickness, and within $14 \%$ in ice extent in both hemispheres. The model captures $56 \%$ of the variance of ice thickness along the 1993 submarine track in the Arctic. The simulated ridged ice has various thicknesses, up to $20 \mathrm{~m}$ in the Arctic and $16 \mathrm{~m}$ in the Southern Ocean. Most of the simulated ice is 1-3 m thick in the Arctic and 1-2 $\mathrm{m}$ thick in the Southern Ocean. The results indicate that, in the Atlantic-Indian sector of the Southern Ocean, the oceanic heating, mainly due to convective mixing, can readily exceed the atmospheric cooling at the surface in midwinter, thus forming a polynya. The results also indicate that the West Spitzbergen Current is likely to bring considerable oceanic heat (generated by lateral advection and vertical convection) to the Odden ice area in the Greenland Sea, an important factor for an often tongue-shaped ice concentration in that area.
\end{abstract}

\section{Introduction}

Sea ice in the polar oceans plays an important role in global climate. The presence of sea ice significantly modifies the air-sea exchange and therefore impacts the atmospheric and oceanic circulation. The climatic importance of sea ice has motivated researchers to improve sea ice morphology, dynamics, and thermodynamics in large-scale sea ice models. The status of sea ice models and model development has been given in a number of recent overviews (Randall et al. 1998; Steele and Flato 2000). Typically, sea ice has various thicknesses and these various thicknesses evolve differently in response to dynamic and thermodynamic forcing. Sea ice is also subject to mechanical redistribution due to ridging and rafting. To capture the behavior of sea ice with its variety of thicknesses, it is preferable to employ a thickness

Corresponding author address: Dr. Jinlun Zhang, Polar Science Center, Applied Physics Laboratory, University of Washington, 1013 NE 40th, Seattle, WA 98105-6698.

E-mail: zhang@apl.washington.edu distribution model that describes the evolution of multiple categories of ice thickness and incorporates the ice ridging process (Hibler 1980).

Many of the recently developed multicategory thickness distribution sea ice models for polar research (Flato and Hibler 1995; Schramm et al. 1997; Zhang et al. 1998b, 2000; Arbetter et al. 1999; Meier and Maslanik 1999) are based on the pioneering work by Thorndike et al. (1975), Rothrock (1975), and Hibler (1980). Thorndike et al. (1975) introduced an ice thickness distribution function and developed both Eulerian and Lagrangian equations to describe the evolution of ice thickness distribution in the presence of ice advection, growth, melting, and ridging. Rothrock (1975) established the relationship between the work done on ice through ridging and the work done by the ice interaction force, which led to parameterization of ice strength that links ice thickness distribution to rheological behavior of sea ice (Hibler 1980). The parameterization of ice strength was further improved by Hopkins and Hibler (1991) who, by simulating individual ridge-building 
events, determined the range of the ratio of total energy loss to potential energy change during ridging. Hibler (1980) provided a numerical framework for implementing the Eulerian thickness distribution equation of Thorndike et al. in a large-scale, dynamic thermodynamic sea ice model with multiple ice thickness categories. The Hibler-type Eulerian model solves one equation to determine ice thickness distribution. This is in contrast with recently developed Lagrangian thickness distribution models that solve two equations to determine ice thickness distribution: one for ice concentration, and the other for ice volume per unit area (Bitz et al. 2001; Melia 2002). Another feature of the Eulerian model is that the model's mechanical redistributor, used to calculate ice ridging, is time independent and therefore does not need to be updated at each time and at each model grid cell (Hibler 1980; Zhang and Rothrock 2001). Arguably, this feature allows the model to increase ice thickness categories without substantially increasing computation cost. The thickness distribution sea ice model computes ice motion and deformation, simulates ice ridging, and calculates thermodynamic growth and decay for each thickness category. Therefore the model captures the essential coupling of dynamic and thermodynamic sea ice processes.

The Hibler (1980) Eulerian thickness distribution sea ice model has been improved by Flato and Hibler (1995) to simulate the evolution of snow by solving a snow thickness distribution equation. Flato and Hibler also investigated the model's sensitivity to the mechanical parameters in the ice thickness distribution. The model has been further improved by Zhang and Rothrock (2001) to simulate the evolution of ice enthalpy by solving an enthalpy distribution equation. The thickness and enthalpy distribution (TED) model conserves both ice mass and ice thermal energy in the presence of ice advection, growth, melt, and ridging. It also utilizes Winton's (2000) nonlinear thermodynamics to obtain a more realistic seasonal cycle of ice thickness.

The dynamical component of the thickness distribution model has also been improved. Hibler (1980) originally used a point successive relaxation (PSR) technique to solve the ice momentum equation governed by a viscous-plastic rheology with an elliptical plastic yield curve (Hibler 1979). An improved ice dynamics model was later implemented by Zhang and Hibler (1997) to solve such an ice momentum equation. This dynamics model employs a semi-implicit line successive relaxation (LSR) technique and a tridiagonal matrix solver procedure, which is more efficient numerically and better behaved in plastic solution than the PSR scheme (see Song 1994). Therefore the LSR dynamics solver is used in the TED model for calculating ice motion, deformation, and ridging.

Although the Eulerian thickness distribution model has been used successfully for regional studies of Arctic climate, it has not been used, to our knowledge, to model global sea ice. In this study, we intend to implement the TED sea ice model on a global scale. Since global modeling generally demands more computer resources, two necessary model improvements were made to enhance the numerical efficiency and versatility of the global TED model. The model has been developed based on a generalized orthogonal curvilinear coordinate (GOCC) system. A GOCC system allows a coordinate transformation that displaces the "north pole" of the model grid, or the northern grid pole, into landmasses. The north pole of a model grid is where curvilinear coordinate lines converge and the length of the sides of the model grid cells approaches zero. With the north pole of the model grid being displaced on land, it is possible to avoid the so-called pole problem, which is associated with the convergence of meridians at the geographic North Pole within the computational domain in a common spherical coordinate system. This allows a larger numerical time step interval and therefore a better computational efficiency (e.g., Smith et al. 1995).

The TED model has been designed to run on parallel computers. This improvement allows efficient model runs on modern computers with various parallel processors. It also allows the model to be coupled easily to a parallel ocean model. In this study, we have coupled the parallel TED sea ice model to the Parallel Ocean Program (POP), the parallel ocean model developed at the Los Alamos National Laboratory. One purpose of this study is to present such a coupled parallel ocean and ice model (POIM) implemented on a global scale, and to examine its validity in simulating sea ice in both polar oceans, which is done by comparing model output with buoy observations of ice motion, submarine observations of ice thickness, and satellite observations of ice concentration. Another purpose is to study the different characteristics of ice thickness distribution in both polar oceans. The POIM's behavior in parallel computing is also evaluated. In section 2 the POIM is presented. The derivation of the components of sea ice physical variables in a GOCC system is given in some detail in appendix A. The numerical framework of the model is described in section 3. Parallel computing of the TED model is briefly described in appendix B. In section 4 the model results are presented and compared with the observations. Conclusions are given in section 5 .

\section{Model description}

The POIM is a coupled global model in a GOCC system, consisting of the POP ocean model and a TED sea ice model. The basic setting for the POIM is as follows. First, the ice model is driven by atmospheric forcing, which consists of surface winds, surface air temperature, humidity, downwelling longwave and shortwave radiative fluxes, precipitation, and evaporation. The ice model then supplies surface heat, salt (or freshwater), and momentum fluxes to the ocean as ocean surface boundary conditions. In turn, the ocean model supplies current and heat-exchange information to the 
ice model. A description of the POIM, which focuses on the ice model, is given below.

\section{a. The TED sea ice model}

The multicategory TED sea ice model consists of six main components: a momentum equation that determines ice motion, a viscous-plastic ice rheology that determines the relationship between ice internal stress and ice deformation (Hibler 1979), a heat equation that determines ice growth/decay and ice temperature, an ice thickness distribution equation that conserves ice mass (Thorndike et al. 1975), an ice enthalpy distribution equation that conserves ice thermal energy (Zhang and Rothrock 2001), and a snow thickness distribution equation that conserves snow mass (Flato and Hibler 1995). The ice momentum equation is solved using Zhang and Hibler's (1997) ice dynamics model. The heat equation is solved, over each ice thickness category, using Winton's (2000) three-layer thermodynamic model, which divides the ice in each category into two layers of equal thickness beneath a layer of snow. The equations involving vectors or tensors are briefly described here.

The ice momentum equation is described by (Hibler 1979)

$$
\begin{aligned}
m \frac{D \mathbf{u}}{\partial t}= & -m \tilde{f} \mathbf{e}_{3} \times \mathbf{u}+\tau_{a}+\tau_{w} \\
& -m g_{a} \nabla_{H} p(0)+\nabla \cdot \sigma,
\end{aligned}
$$

where $m$ is ice mass per unit area; $\mathbf{u}=u_{1} \mathbf{e}_{1}+u_{2} \mathbf{e}_{2}$ is ice velocity; $\mathbf{e}_{1}, \mathbf{e}_{2}$, and $\mathbf{e}_{3}$ are the unit base vectors in the GOCC system; $\tilde{f}$ is the Coriolis parameter; $\tau_{a}$ is air drag; $\tau_{w}$ is water drag; $g_{a}$ is the acceleration due to gravity; $p(0)$ is sea surface dynamic height; and $\sigma$ is an ice internal stress tensor $\left(\sigma_{i j}\right)$. The air drag is a combination of one on ice and one on open water, weighted by ice concentration and open-water fraction, respectively. The open-water air drag is determined following the technical note written by the National Center for Atmospheric Research (NCAR) Oceanography Section (1996) and is described by (see Large and Pond 1981)

$$
\tau_{a}=\rho_{a} C_{a}\left|\mathbf{U}_{a}\right| \mathbf{U}_{a},
$$

where $\mathbf{U}_{a}$ is surface $(10 \mathrm{~m})$ wind velocity, $C_{a}=10^{-3}$ $\left(2.70 /\left|\mathbf{U}_{a}\right|+0.142+0.0764\left|\mathbf{U}_{a}\right|\right)$ is the air drag coefficient, and $\rho_{a}$ is air density. The air drag coefficient for ice was set at 0.002 following Overland (1985). Description of the water drag can be found in Hibler (1979). The divergence of the ice stress tensor in (1) represents an internal ice interaction force. The stress tensor is related to ice strain and strength following the viscous-plastic constitutive law such that

$$
\sigma_{i j}=2 \eta \dot{\varepsilon}_{i j}+(\zeta-\eta) \dot{\varepsilon}_{k k} \delta_{i j}-\frac{P^{*}}{2} \delta_{i j},
$$

where $\dot{\varepsilon}_{i j}$ is ice strain rate, $P^{*}$ is ice strength, $\zeta$ and $\eta$ are the bulk and shear viscosities, and $\delta_{i j}$ is the Kro- necker delta. The nonlinear viscosities are based on an elliptical yield curve and given by (see Hibler 1979)

$$
\zeta=P / 2 \Delta, \quad \eta=\zeta / \tilde{e}^{2},
$$

where $\tilde{e}=2$ is the ratio of the principal axes of the elliptical yield curve and $\Delta=\left[\left(\dot{\varepsilon}_{11}^{2}+\dot{\varepsilon}_{22}^{2}\right)\left(1+\tilde{e}^{-2}\right)+\right.$ $\left.4 \tilde{e}^{-2} \dot{\varepsilon}_{12}^{2}+2 \dot{\varepsilon}_{11} \dot{\varepsilon}_{22}\left(1-\tilde{e}^{-2}\right)\right]^{1 / 2}$. The ice thickness distribution equation is written as (see Thorndike et al. 1975; Hibler 1980)

$$
\frac{\partial g}{\partial t}+\boldsymbol{\nabla} \cdot(\mathbf{u} g)+\frac{\partial(f g)}{\partial h}=\psi+F_{L},
$$

where $g$ is ice thickness distribution, which is a normalized probability density function defined as $\int_{h_{1}}^{h_{2}} g(h)$ $d h=r\left(h_{1}, h_{2}\right) / R, h$ is ice thickness, $R$ is the area of a fixed region $\mathbf{R}, r\left(h_{1}, h_{2}\right)$ is the area within $\mathbf{R}$ covered by ice with thickness between $h_{1}$ and $h_{2}, f$ is ice growth rate, $\psi$ is a redistribution function due to ridging, and $F_{L}$ is the source term for lateral melting. Equation (5) represents an Eulerian description of ice thickness distribution in a three-dimensional $(x-y-h)$ space, where ice thickness $h$ is an independent coordinate. The thickness redistribution function in (5) is defined by

$$
\begin{aligned}
\psi=c_{1} \delta(h)+c_{2}[ & -P(h) g(h) \\
& \left.+\int_{0}^{\infty} \gamma\left(h^{\prime}, h\right) P\left(h^{\prime}\right) g\left(h^{\prime}\right) d h^{\prime}\right],
\end{aligned}
$$

where

$$
\begin{aligned}
c_{1} & =\left(P^{*}\right)^{-1} \sigma_{i j} \dot{\varepsilon}_{i j}+\dot{\varepsilon}_{k k}, \\
c_{2} & =\frac{\left(P^{*}\right)^{-1} \sigma_{i j} \dot{\varepsilon}_{i j}}{\int_{0}^{\infty}\left[P(h) g(h)-\int_{0}^{\infty} \gamma\left(h^{\prime}, h\right) P\left(h^{\prime}\right) g\left(h^{\prime}\right) d h^{\prime}\right] d h},
\end{aligned}
$$

$P$ is a function specifying which categories of ice participate in ridging, and $\gamma\left(h^{\prime}, h\right)$ is a redistributor of the thickness distribution (Hibler 1980). The ice enthalpy distribution equation is written as (see Zhang and Rothrock 2001)

$$
\frac{\partial e}{\partial t}+\nabla \cdot(\mathbf{u} e)+\frac{\partial(f e)}{\partial h}=H F_{L}+\Phi,
$$

where $e=g H$ is the ice enthalpy distribution function, $H(h)=\int_{0}^{h} \rho c_{p} T(z, h) d z$ is ice enthalpy per unit area, $\rho$ is ice density, $c_{p}$ is ice heat capacity, $T$ is ice temperature, $z$ is ice depth (measured positive upward from the bottom of the ice), and $\Phi$ is the enthalpy redistribution function. The enthalpy redistribution function is written as

$$
\begin{aligned}
\Phi=c_{2} & -P(h) e(h) \\
& \left.+\int_{0}^{\infty} \gamma\left(h^{\prime}, h\right) P\left(h^{\prime}\right) e\left(h^{\prime}\right) \frac{h}{h^{\prime}} d h^{\prime}\right] .
\end{aligned}
$$

Finally, the snow thickness distribution is written as 

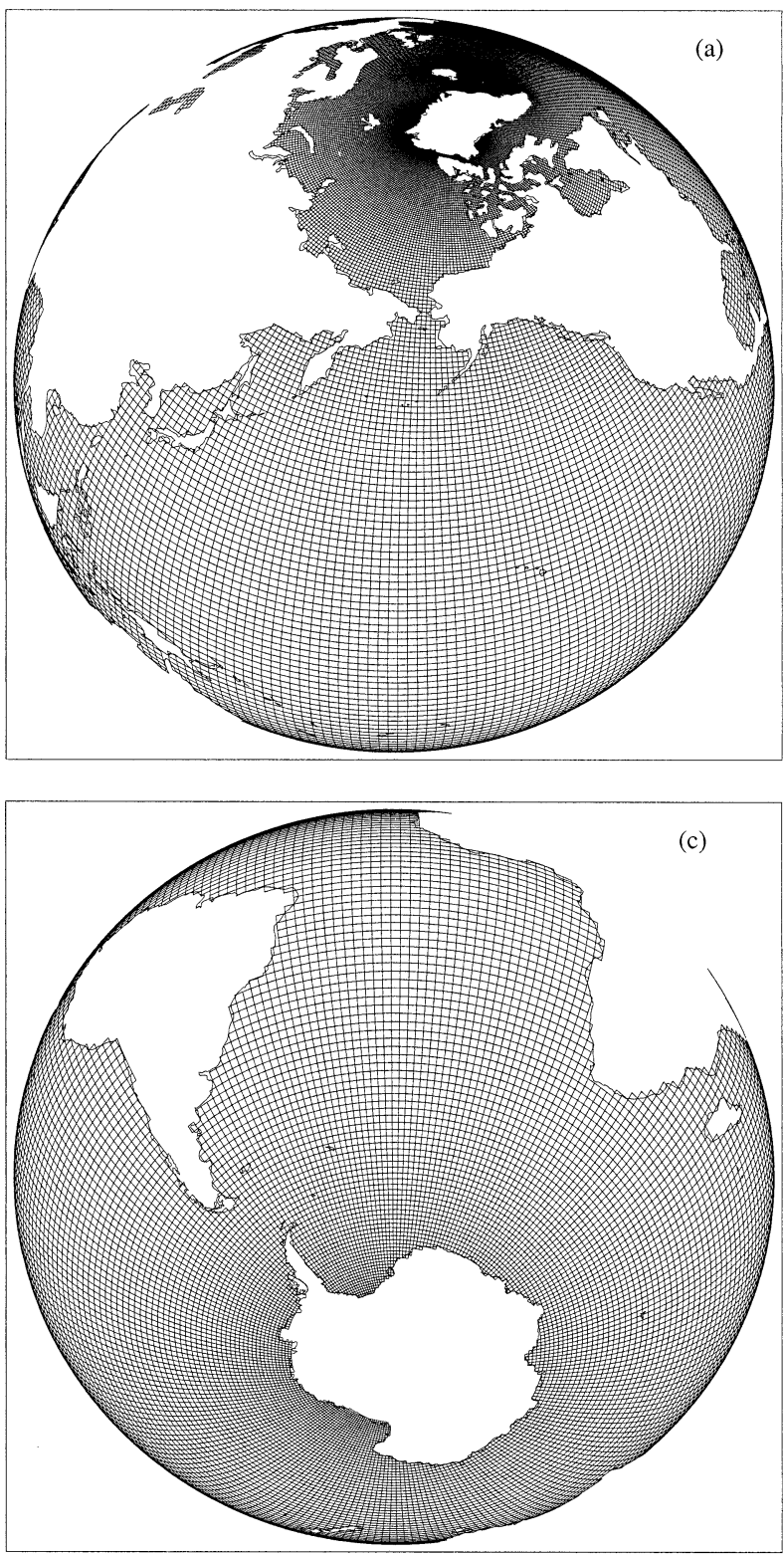

TABLE 1. Thickness of ocean levels used in the POIM.

\begin{tabular}{cccc}
\hline \hline Level & Thickness $(\mathrm{m})$ & Level & Thickness $(\mathrm{m})$ \\
\hline 1 & 10.0 & 2 & 10.0 \\
3 & 10.0 & 4 & 10.0 \\
5 & 10.0 & 6 & 11.4 \\
7 & 18.5 & 8 & 27.5 \\
9 & 38.8 & 10 & 52.8 \\
11 & 70.0 & 12 & 90.5 \\
13 & 114.7 & 14 & 142.8 \\
15 & 174.9 & 16 & 210.9 \\
17 & 250.3 & 18 & 292.9 \\
19 & 341.8 & 20 & 401.8 \\
21 & 465.2 & 22 & 533.5 \\
23 & 609.3 & 24 & 690.2 \\
25 & 788.5 & & \\
\hline
\end{tabular}

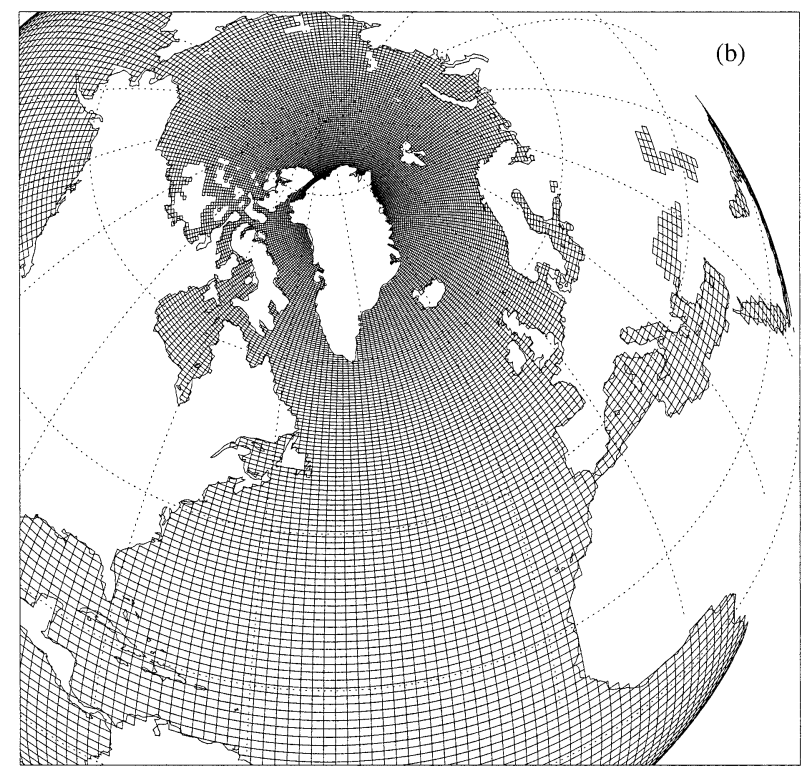

FIG. 1. Three views of the POIM global model grid: (a) Arctic and North Pacific, (b) Arctic and North Atlantic, and (c) Antarctic and South Atlantic.

$$
\frac{\partial h g_{s}}{\partial t}+\boldsymbol{\nabla} \cdot\left(\mathbf{u} h g_{s}\right)+\frac{\partial\left(f h g_{s}\right)}{\partial h}=S,
$$

where $g_{s}$ is the snow thickness distribution function and $S$ is a source term given in detail by Flato and Hibler (1995).

Equations (1)-(9) contain either tensor or vector operators, the components of which are described in appendix A. The parameters governing the ridging process, such as the frictional dissipation coefficient, the ridge participation constant, and shear ridging parameter, are given by Flato and Hibler (1995, see their Table 3 for the standard case). All the snow and ice thermodynamic parameters used here are also given by Flato and Hibler (1995, see their appendix). 

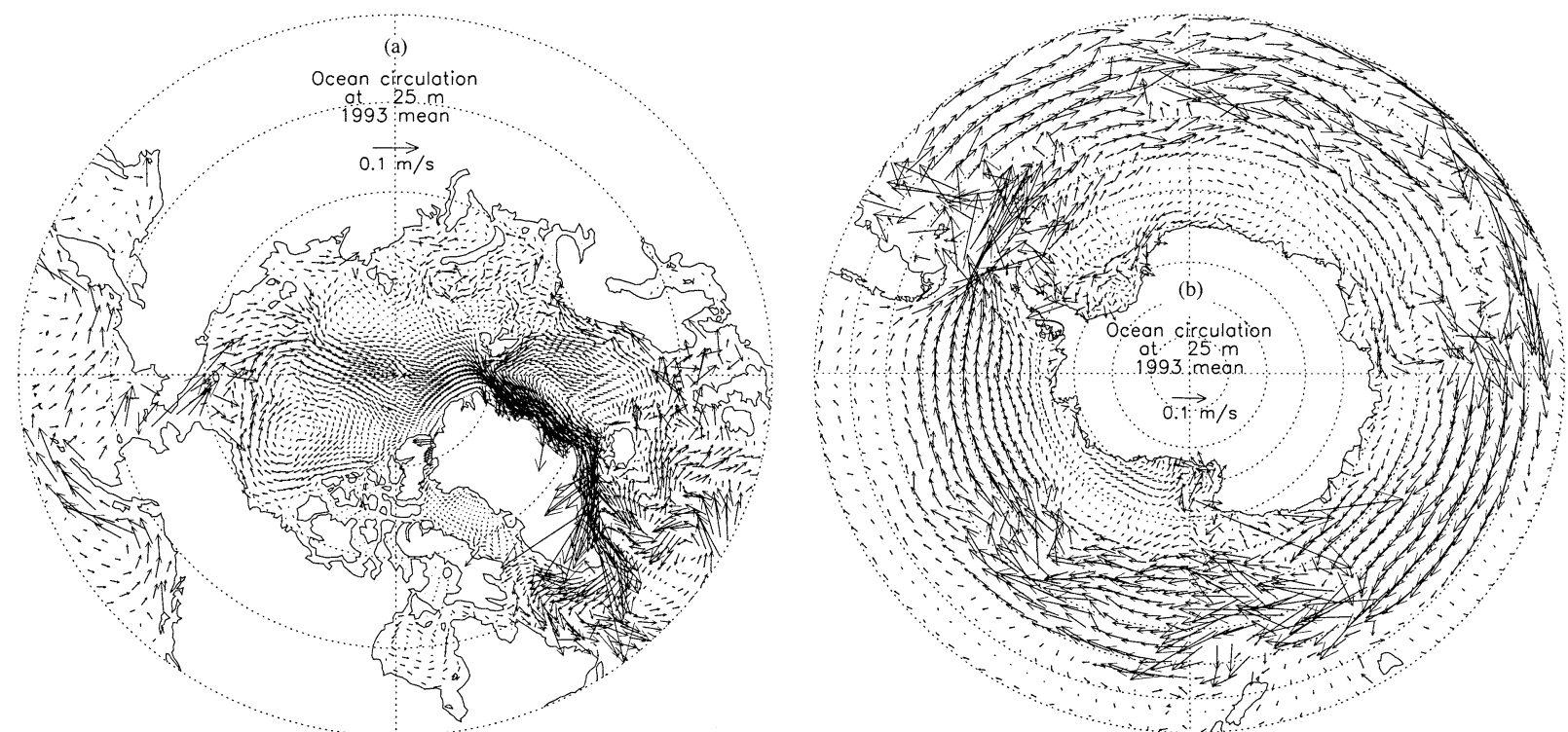

FIG. 2. Simulated annual mean ocean velocity at 25-m depth for (a) the NH and (b) the Southern Ocean. One vector is drawn for every four grid cells.

\section{b. The POP ocean model}

Briefly, the POIM's ocean model is based on the POP ocean model. The POP model is a Bryan-Cox-Semtnertype ocean model (Bryan 1969; Cox 1984; Semtner 1986) with numerous improvements, including an implicit free-surface formulation of the barotropic mode and model adaptation to parallel computing (e.g., Smith et al. 1992; Dukowicz and Smith 1994; Smith et al. 1995). Once the ocean model is coupled to the ice model, the stress into the ocean is the wind stress $\tau_{a}$ plus the ice interaction forcing $\boldsymbol{\nabla} \cdot \sigma$, which follows Hibler and Bryan [(1987), Eq. (2)].

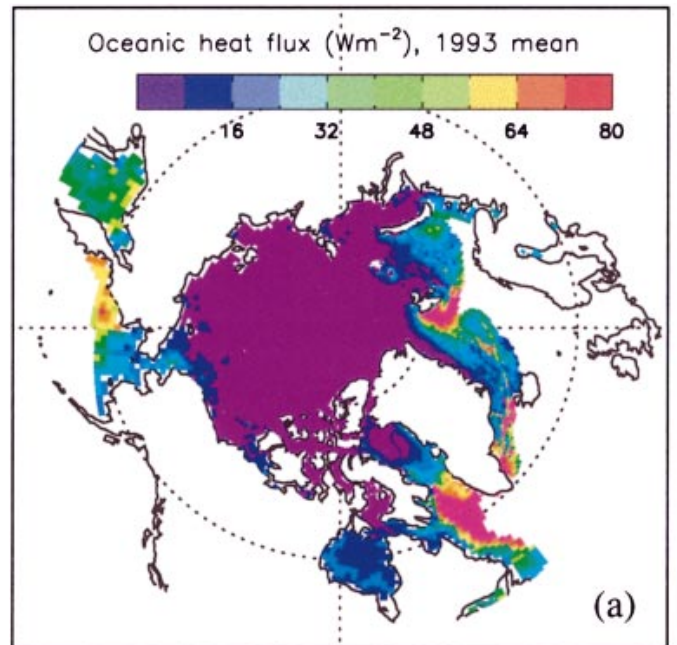

FIG. 3. Simulated annual mean oceanic heat flux in sea-ice-covered areas in (a) the NH and (b) the Southern Ocean. The value for most of the Arctic Basin is about $2.0 \mathrm{~W} \mathrm{~m}^{-2}$.

\section{Numerical framework and surface forcing}

The configuration of the finite-difference grid of the global POIM is shown in Fig. 1. This is a GOCC grid generated using the continuous-differentiable dipole scheme given by Smith et al. (1995). In the northern hemisphere $(\mathrm{NH})$ the model grid is a stretched GOCC grid with the northern grid pole displaced into Greenland at $\left(76^{\circ} \mathrm{N}, 40^{\circ} \mathrm{W}\right)$, so that the model has its highest resolution in the Greenland Sea, Baffin Bay, and the eastern Canadian Archipelago. In the southern hemisphere $(\mathrm{SH})$ the model grid is a regular spherical coordinate grid, or a special GOCC grid. The horizontal

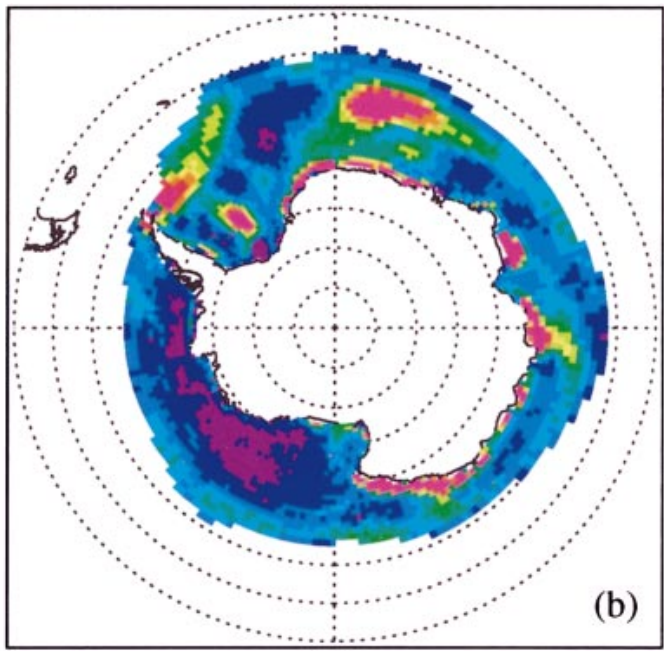




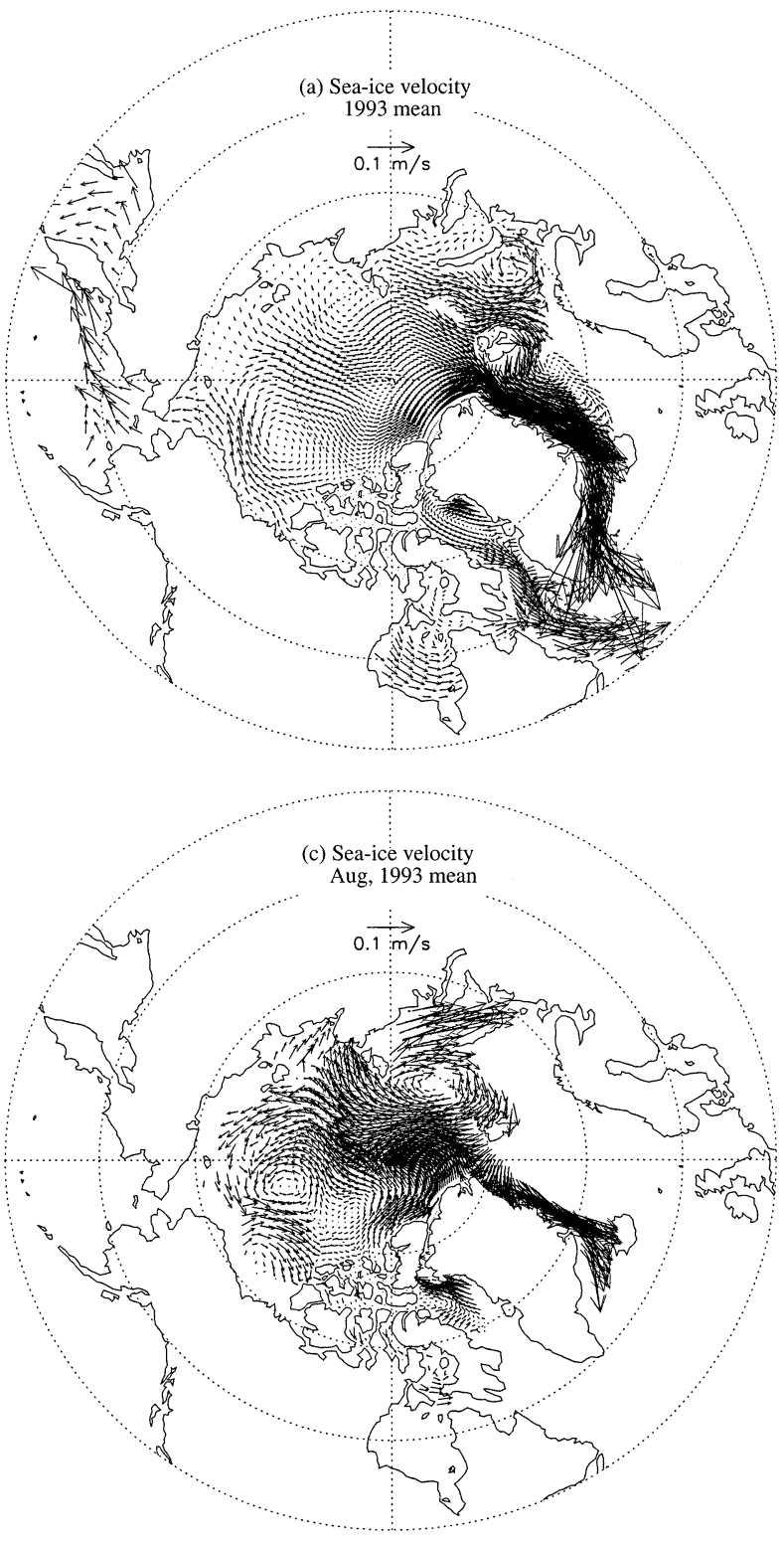

size is $240 \times 216$ with a resolution of $\left\langle 4 / 5^{\circ}\right\rangle$ (brackets denote the average resolution of surface ocean points). The model's vertical dimension has 25 levels of different thicknesses (Table 1) for resolving bottom topography. The global bathymetry dataset is obtained by merging the International Bathymetric Chart of the Arctic Ocean (IBCAO) dataset and the Earth Topography Five Minute Gridded Elevation Data Set (ETOPO5; Holland 2000). The TED model has 12 categories for ice thickness, ice enthalpy, and snow thickness. The 12 ice thickness categories are partitioned following a Gaussian distribution (Hibler 1980) to obtain a thickness mesh that varies smoothly in spacing (see Zhang et al. 2000).

The POIM is driven by daily The (National Centers for Environmental Prediction) NCEP-NCAR reanalysis surface forcing fields (available online at ftp.cdc.noaa.

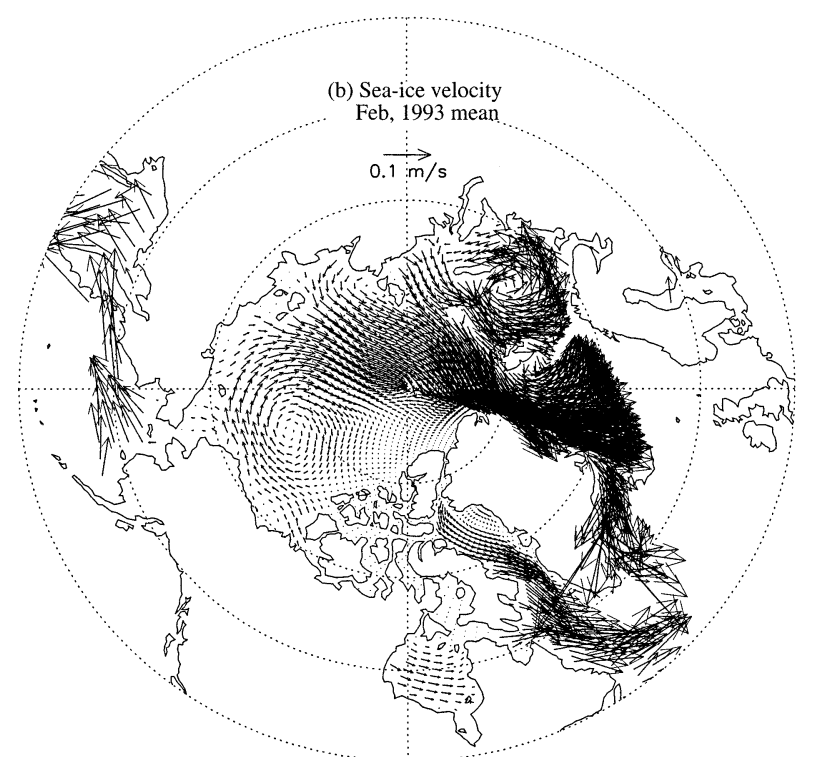

FIG. 4. Simulated mean sea ice velocity in the NH. One vector is drawn for every four grid cells. gov): 10-m winds, $2-\mathrm{m}$ air temperature, specific humidity, downward shortwave and longwave radiative fluxes, precipitation, and evaporation. Because there is no global river runoff input in the model, the surface ocean salinity is restored to the Levitus (1982) salinity climatology with a 1-yr restoring constant. However, the surface ocean temperature is not restored to climatology so that the ice growth, determined by the atmospheric and oceanic heat fluxes, is not affected by the additional heat source due to the surface temperature restoring (see Zhang et al. 1998a).

\section{Results}

With a 1-h time step, the POIM was run for $10 \mathrm{yr}$ of integration using 1984-93 NCEP-NCAR reanalysis 


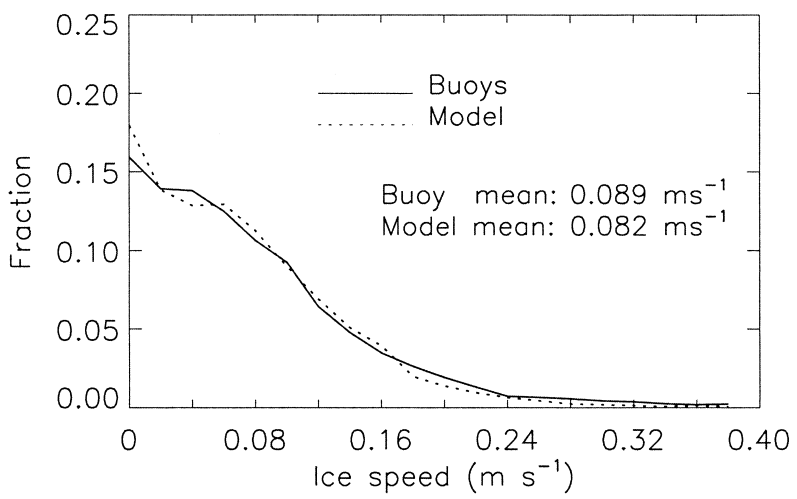

FIG. 5. Distributions of simulated ice speed and observed Arctic buoy speed, based on all the available daily buoy drift data for the Arctic in 1993 and simulated daily ice velocities corresponding to the buoy data.

forcing fields on a cluster of 10 parallel 1-GHz Athlon processors. After the 10-yr simulation from 1984 to 1993, the sea ice and ocean mixed layer were close to steady state. The 1993 model results were then compared with the available 1993 Scientific Ice Expeditions (SCICEX) submarine observations of ice thickness, buoy motion, and satellite-derived ice concentration and extent.

\section{a. Ocean flow and heat flux}

Although this study focuses on the TED model, we show the fields of ocean flow and heat flux calculated by the POP ocean model and supplied to the TED model for calculating ice dynamics and thermodynamics. Figure 2 shows the simulated 1993 mean fields of ocean velocity at the third level of the ocean (at 25-m depth), which roughly represent the surface geostrophic velocity used by the TED model to calculate water drag (see Hibler and Bryan 1987). In the Arctic the POIM captures the anticyclonic ocean circulation over the Beaufort Sea and Canadian Basin and the transpolar drift stream. There is a strong inflow at Bering Strait. Outside the Arctic Basin, the model captures some of the major surface currents, such as the East Greenland, the Norwegian, the West Spitzbergen, the West Greenland, and the Labrador currents. In the Southern Ocean the model captures some basic features of the Antarctic Circumpolar Current. The modeled Antarctic Circumpolar Current appears irregular in width, course, and intensity because of the influence of the Antarctic and adjacent South American landmasses, the prevailing winds, and the existence of the ice cover that alters the transfer of momentum, heat, and mass at the surface.

The simulated oceanic heat flux is shown in Fig. 3. In agreement with Hibler and Bryan (1987), the annual mean oceanic heat flux is small in the Arctic Basin because of well-stratified arctic water associated with a cold halocline layer (Aagaard et al. 1981). It is also small in Baffin Bay and narrow passages in the Canadian
Archipelago. The relatively large oceanic heat flux in the Barents and Greenland Seas is also in agreement with Hibler and Bryan who attributed those large values to the lateral heat transport due to the northward Norwegian and West Spitzbergen Currents. The large values in the Bering Sea may be attributed to the northward Pacific water flow (Fig. 2a), whereas the large values in the Labrador Sea are probably due to strong convective mixing (e.g., Lilly et al. 1999).

The oceanic heat flux in most of the ice-covered portion of the Southern Ocean is considerably larger than in the Arctic Basin. This is because the stratification of the Southern Ocean is weaker and the mixed layer is generally deeper owing to strong upper-ocean stirring associated with the passage of intense cyclones (e.g., McPhee et al. 1996; Ushio et al. 1999). As a result, more heat is brought up from the depths of the ocean through vertical overturning, particularly in an area in the Atlantic-Indian sector.

\section{b. Ice motion}

Figure 4 shows the simulated mean ice velocity fields in the NH. The most notable feature of the simulated annual mean ice motion in the Arctic is an anticyclonic Beaufort gyre and a transpolar drift stream toward Fram Strait (Fig. 4a). This pattern is in agreement with the observed arctic buoy drift (Rigor 1992). The Beaufort gyre and the transpolar stream are particularly strong in midwinter (Fig. 4b). In August of 1993, the Beaufort gyre and the transpolar drift show a reversal (Fig. 4c), which is consistent with the International Arctic Buoy Program (IABP; see Rigor and Colony 1995) report that shows cyclonic buoy motion associated with a cyclone in the Canadian Basin. Generally speaking, however, such a flow reversal does not last long and, as a result, the annual mean ice flow pattern maintains an anticyclonic Beaufort gyre and a transpolar stream toward Fram Strait (Fig. 4a).

In order to assess how well the model simulates the ice motion in the Arctic, Fig. 5 compares the distribution of the simulated ice speed and observed buoy drift speed. The observed buoy drift velocities are provided by IABP (Rigor and Colony 1995). These two speed distributions are calculated based on all the available (11 172) daily Arctic buoy drift velocities in 1993 and the simulated daily mean ice velocities at the locations of the buoys. Compared to the buoy drift data, the model overestimates ice stoppage with a slightly larger fraction of zero velocity. The Arctic buoys have a mean drift speed of $0.089 \mathrm{~m} \mathrm{~s}^{-1}$ in 1993, whereas the simulated mean ice speed is $0.082 \mathrm{~m} \mathrm{~s}^{-1}$ (Fig. 5). Thus statistically, the simulated ice moves about $8 \%$ slower than the observed buoy drift.

The simulated mean ice velocity fields for the Southern Ocean are shown in Fig. 6. Corresponding to the Antarctic Circumpolar Current, the simulated ice drift exhibits a circumpolar drift pattern near the ice edge 

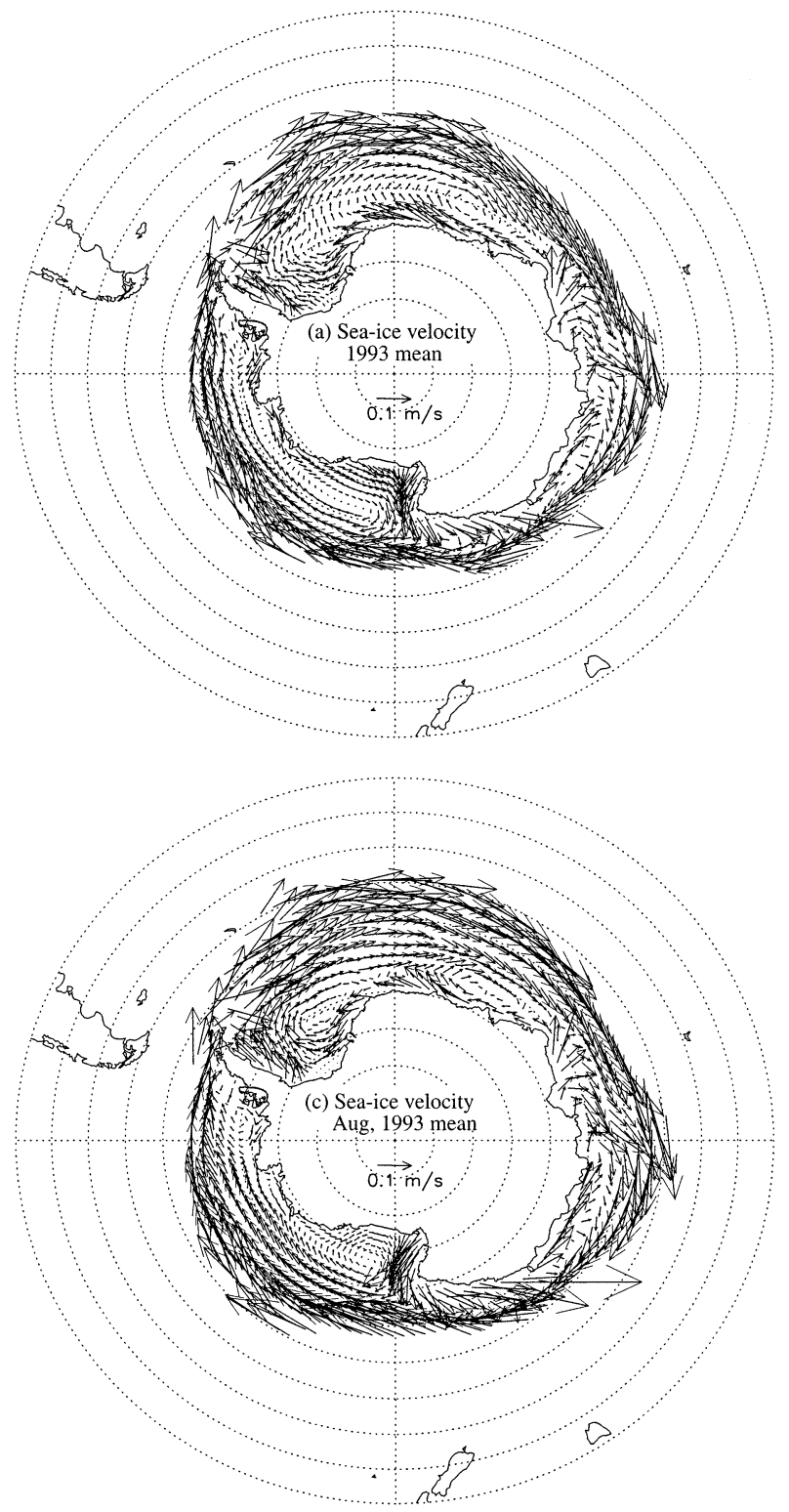

during most of the year, with maximum mean velocities as large as $0.2 \mathrm{~m} \mathrm{~s}^{-1}$ (Figs. 6a and 6c). Near shore, however, the simulated prevailing ice drift is in the direction opposite the circumpolar drift. This feature is present in observations (Drinkwater and Liu 1999; Heil and Allison 1999). Also present in observations is a strong cyclonic gyre in either the Weddell Sea or the Ross Sea (Kottmeier and Sellmann 1996; Drinkwater and Liu 1999). In midsummer (Fig. 6b), the ice extent is substantially reduced and the drift pattern in the Weddell Sea changes to strong offshore ice motion. Offshore ice motion also occurs in part of the Ross Sea.

\section{c. Ice growth and melt}

Figure 7 shows the simulated monthly mean thermodynamic ice growth rates for February and August

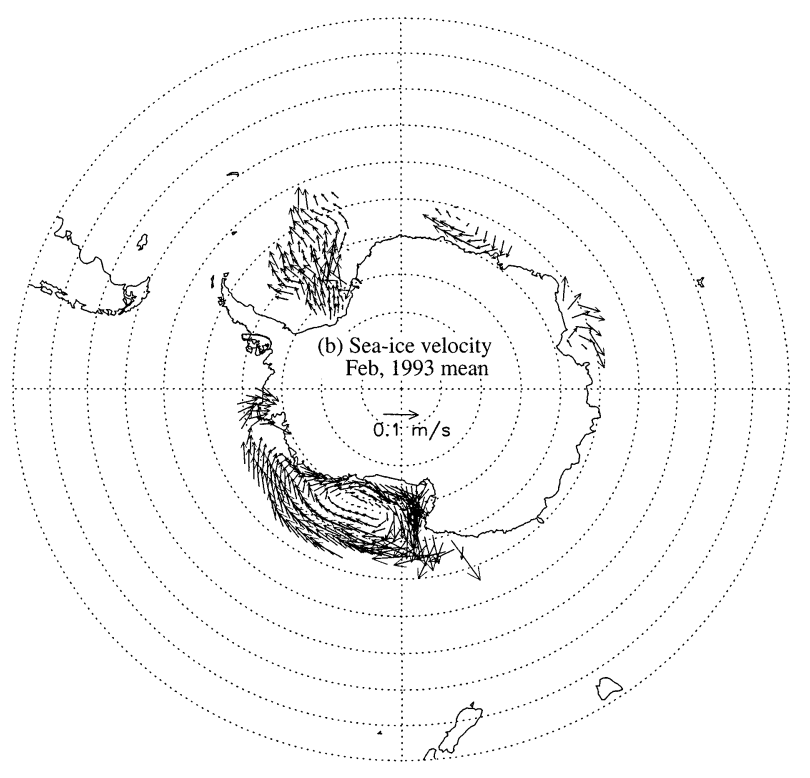

FIG. 6. Simulated mean ice velocity in the Southern Ocean. One vector is drawn for every four grid cells.

1993. In the NH midwinter, the model estimates ice growth over the entire ice-covered ocean (Fig. 7a). The largest ice growth occurs in the Labrador, Greenland, Barents, and Okhotsk Seas, where ice is generally thin. The smallest ice growth takes place near and in the Canadian Archipelago where ice is generally thick. During midsummer, ice melts everywhere over the ice-covered ocean (Fig. 7b), as expected. The eastern Arctic experiences the largest ice melting, whereas ice melting in the Canadian Archipelago and Baffin Bay area is relatively small.

In the $\mathrm{SH}$, the model estimates strong ice growth over a large area during midwinter (Fig. 7d). Interestingly, the spatial pattern of the simulated ice growth resembles that of the simulated oceanic heat flux (Fig. 3b). During midsummer, the model estimates ice melting every- 

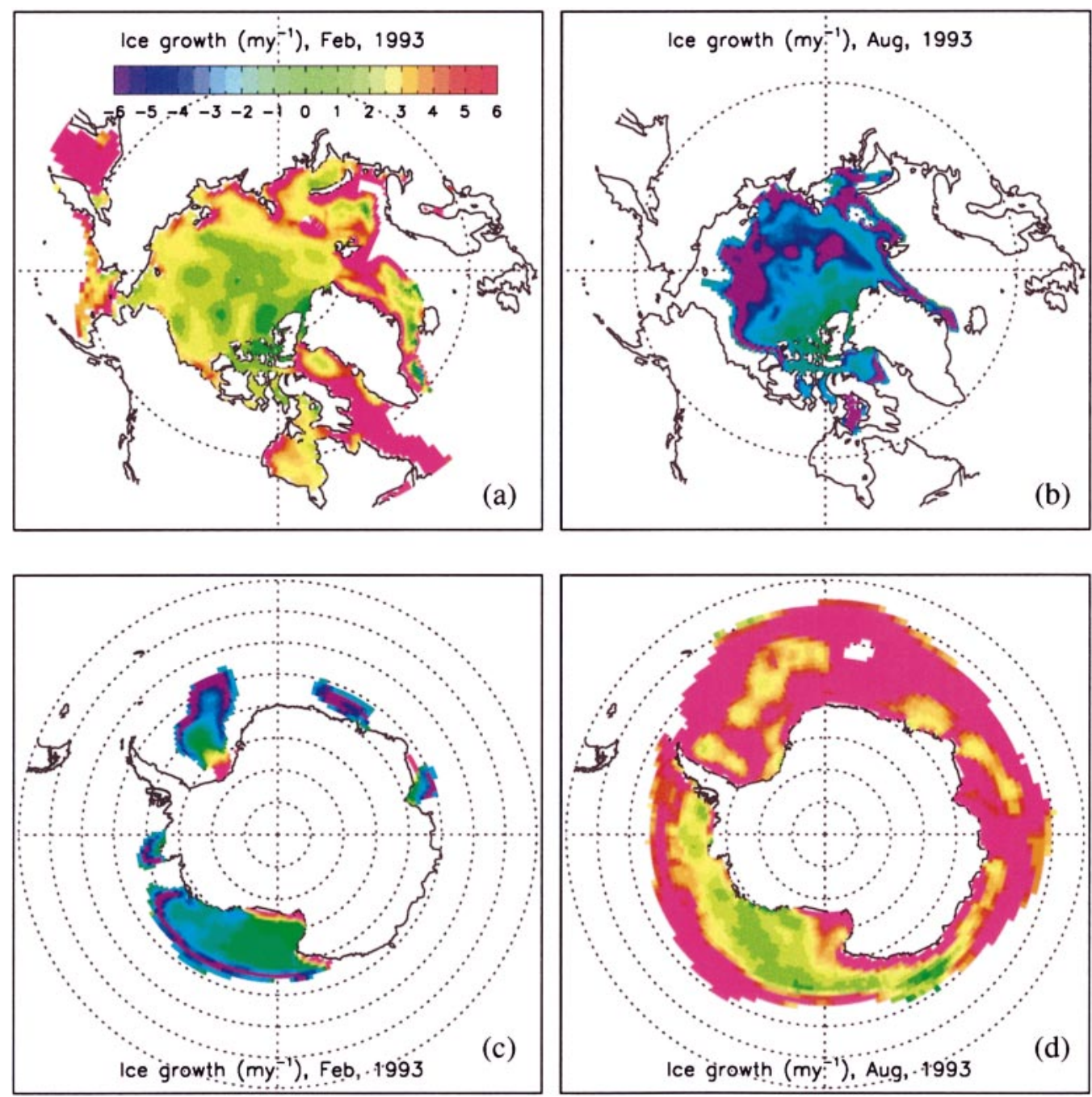

Fig. 7. Simulated mean ice growth rate fields.

where, except near the Filchner Ice Shelf in the Weddell Sea and near the Ross Sea Ice Shelf. These two locations see significant ice growth during midsummer because there is strong offshore ice drift in both areas (Fig. 6c) that creates open water or ice divergence. At the same time, the NCEP-NCAR reanalysis surface air temperature data used to drive the POIM generally remain below freezing [in line with the Antarctic February climatological surface air temperature shown in Zwally et al. (1983)], which may lead to ice production over these areas of ice divergence even in midsummer. Summer observations of ice growth/decay in these two areas would shed light on this.

\section{d. Ice concentration and extent}

The satellite-observed ice edge and the model-simulated fields of ice concentration for February and August 1993 are shown in Fig. 8. Here, the simulated ice concentration is defined as $1-G_{1}$, where $G_{1}$ is the fraction of area taken by the open-water category; that is, the first ice thickness category illustrated in Fig. 1 of Zhang et al. (2000). The observed ice edge is defined to follow the contour of 0.1 ice concentration obtained from satellite observations. Strictly speaking, the simulated and observed ice concentrations are not defined equally. Observed ice concentration is derived from remotely sensed brightness temperature. Nevertheless, here the defined ice edge is plotted together with the simulated ice concentration to roughly evaluate the model's behavior in predicting ice extent.

In the $\mathrm{NH}$, the simulated ice edge for midwinter is close to the observed ice edge in the Okhotsk, Bering, and Labrador Seas (Fig. 8a). However, the model overestimates ice extent in the Barents and Greenland Seas. Perhaps the surface air temperature forcing over these areas is slightly low. Or perhaps the relatively warmer Norwegian and the West Spitzbergen Currents (Fig. 2a) are not strong enough to push the ice edge farther north in the Barents and Greenland Seas. However, by lateral 

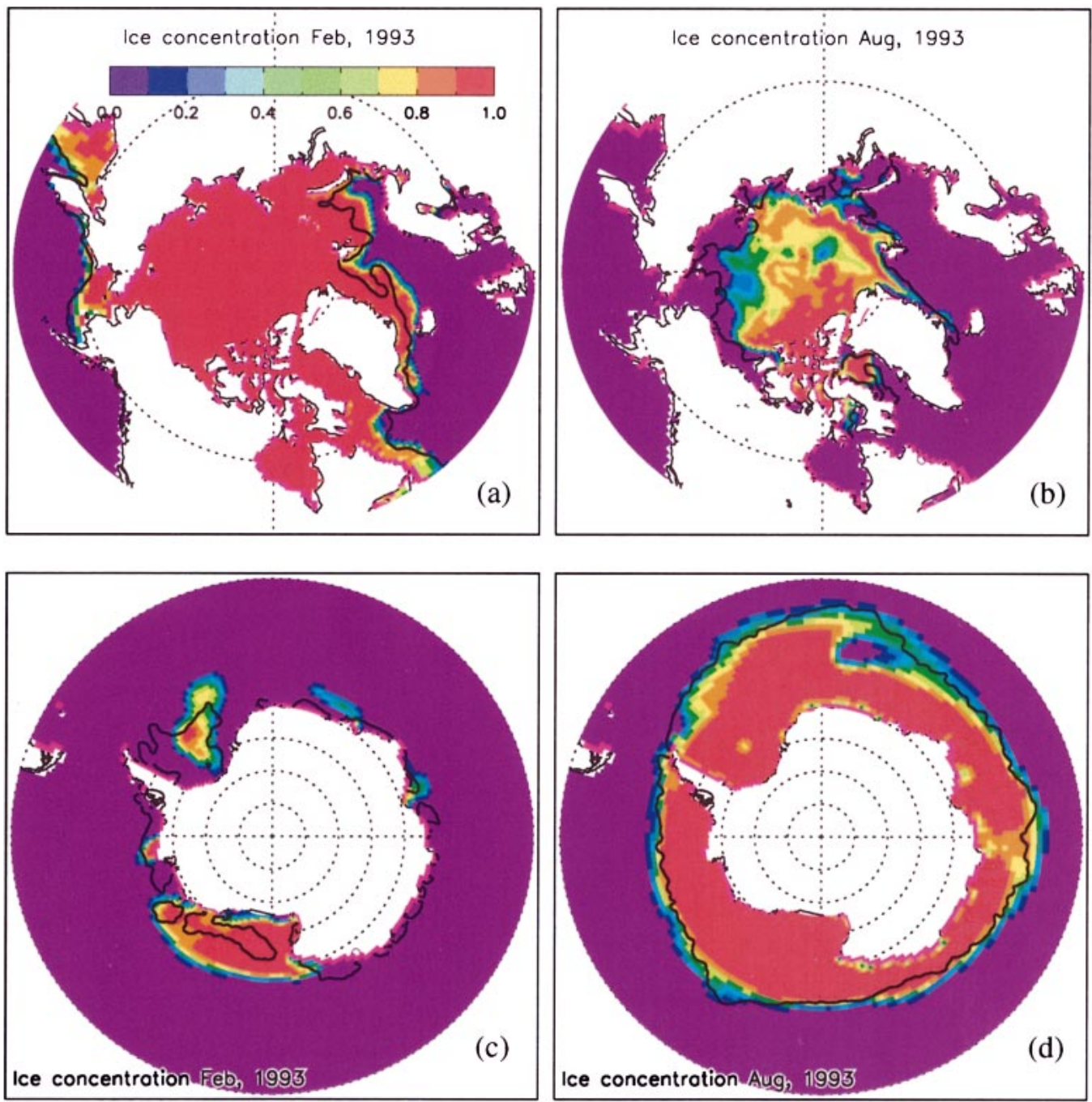

FIG. 8. Simulated mean ice concentration (fraction) fields (in colors) and observed mean ice edge (think black line). The observed ice edge is defined by 0.1 ice concentration derived from observations of satellite sensors, the Special Sensor Microwave Imager (SSM/I). The satellite data were provided by the National Snow and Ice Data Center.

advection and convective mixing the West Spitzbergen Current appears to bring considerable oceanic heat to the south of Spitzbergen and the east of Fram Strait (Fig. 3a), which tends to create an Odden ice tongue there. Obviously, the model is not fully successful in capturing the tongue-shaped ice concentration observed by satellite sensors. In midsummer, the model somewhat underestimates ice extent in some areas such as the east Siberian, Kara, and Beaufort Seas. However, it slightly overestimates ice extent in Baffin Bay (Fig. 8b). The $\mathrm{NH}$ ice extent varies seasonally, and the model overestimates ice extent all year long (Fig. 9a). Although the simulated ice extent is perfectly aligned in phase with the observed ice extent (the correlation between the simulated and observed ice extents is 1.00), the model creates a mean bias of $1.2 \times 10^{12} \mathrm{~m}^{2}$. This means that the simulated mean $\mathrm{NH}$ ice extent is about $10 \%$ larger than observations.

In the $\mathrm{SH}$, the model somewhat overestimates midwinter ice edge in comparison with the observed ice edge (Fig. 8d). Also, the model simulates a polynya in the Atlantic-Indian sector of the Southern Ocean, which is apparently caused by the model's generation of strong oceanic heat flux in the area (Fig. 3b). This area is where a polynya of comparable or even larger size was often observed in some other years (Zwally et al. 1983), but not in 1993. During midsummer, the ice cover in the Southern Ocean shrinks substantially and the model appears to have difficulty in capturing the rapidly shrinking ice extent. Consequently, the model underestimates or overestimates ice extent over several sectors of the Southern Ocean. How the model behaves in simulating 


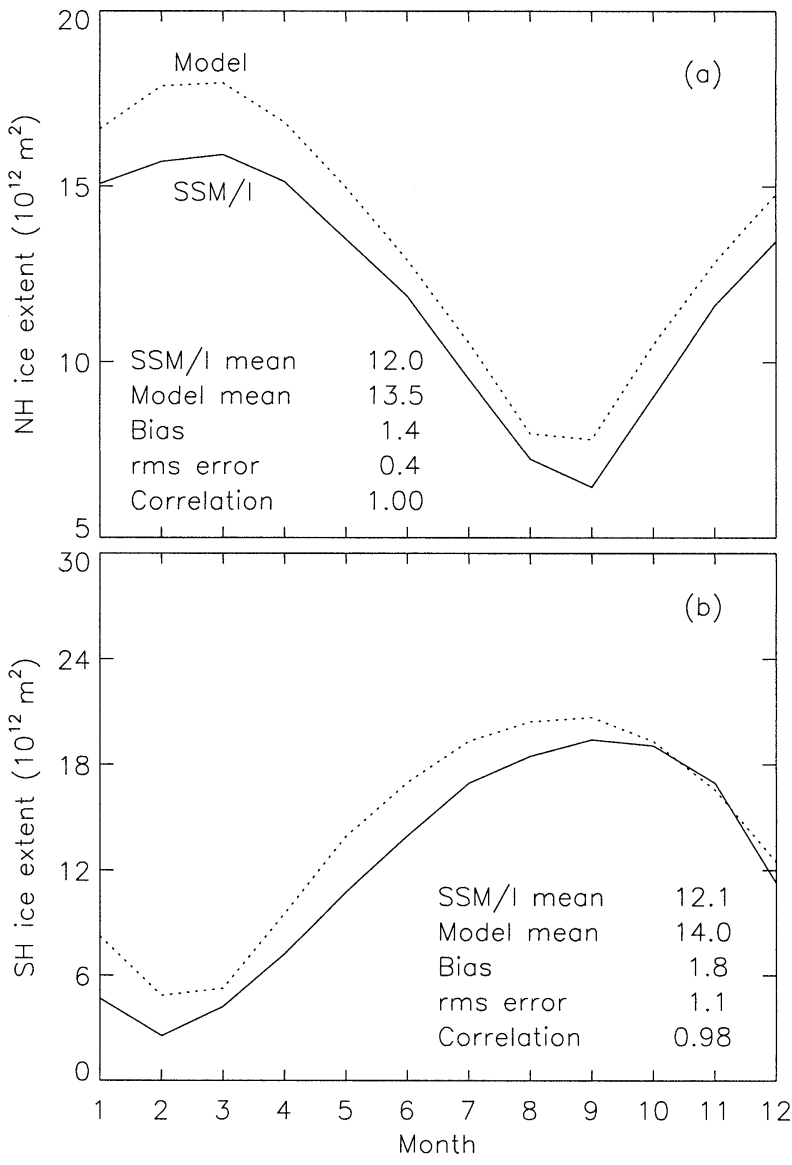

FIG. 9. Model-simulated and SSM/I-observed monthly mean ice extents. Extents are calculated for ice concentration larger than 0.15. Listed in the panels are statistical values of the modeled and observed ice extents.

$\mathrm{SH}$ ice extent for other months is illustrated in Fig. 9b. The model compares well with satellite observations for October-December, but it overestimates ice extent for the rest of the year. The mean bias is $1.7 \times 10^{12} \mathrm{~m}^{2}$, which means that on average the simulated ice extent is about $14 \%$ larger than the observed ice extent. Moreover, the correlation between the simulated and observed extents is 0.98 , which means that they are not perfectly aligned in phase.

\section{e. Ice thickness}

The simulated fields of mean ice thickness for February and August 1993 are shown in Fig. 10. In the NH the general pattern of the fields is very thick ice off the Canadian Archipelago and North Greenland coast (maximum mean ice thickness $6 \mathrm{~m}$ ) and thinner ice in the eastern Arctic (Figs. 10a and 10b). This agrees with the pattern observed by Bourke and McLaren (1992). In the $\mathrm{SH}$, the simulated ice is generally thinner than its counterpart in the Arctic, as the maximum mean ice thickness is approximately $4.0 \mathrm{~m}$ in midwinter and $3.5 \mathrm{~m}$ in mid- summer in the Ross Sea (Fig. 10d). In particular, the simulated mean ice thickness is generally below $1.5 \mathrm{~m}$ in the Atlantic sector of the Southern Ocean, which is consistent with observations (Wadhams et al. 1987). The generally large oceanic heat flux in the Southern Ocean (Fig. 3b) may contribute to a thinner ice cover than in the Arctic.

In order to evaluate the model's behavior in simulating ice thickness in the Arctic, we compared the simulated ice thickness with the submarine observed ice thickness data, which are provided by the National Snow and Ice Data Center (Fig. 11). The submarine data were acquired by a cruise in September of 1993. The track of the cruise, along which the thickness data are available, is plotted in the lower panel of Fig. 11. Each available datum represents an average ice thickness over a distance of $\sim 10-50 \mathrm{~km}$ along the track. For comparison, we sampled the modeled ice thickness at the same time and place of each observed thickness datum. Thus the comparisons are based on the modeled ice thickness estimates that are taken from grid cells in a GOCC system and the observed data that were collected along the course of the cruise.

Figure 11 shows that the POIM does not create enough ice near location A; it overestimates ice thickness between $\mathrm{E}$ and $\mathrm{F}$, while underestimating ice thickness between $\mathrm{F}$ and $\mathrm{J}$. The best match between the modeled and the observed ice thickness occurs between D and E. The table in Fig. 11a provides a statistical analysis of the modeled and observed ice thicknesses along the 1993 submarine track. The mean model bias against the observations is relatively small $(2.09-2.28=-0.19$ $\mathrm{m},<9 \%$ bias). The rms error or error standard deviation is $0.60 \mathrm{~m}, 26 \%$ of the submarine mean thickness $(2.28$ $\mathrm{m})$. The spatial correlation between the modeled and the observed thicknesses along the entire track is 0.75 . This means that the model captures $56 \%$ of the variance of ice thickness along the submarine track over a large area in the Arctic.

The simulated thickness distributions are shown in Figs. 12 and 13. Since the models have 12 thickness categories, the distributions are plotted for 12 bins. The model simulates ice in a range of thicknesses owing mainly to the ridging process. The simulated ridged ice in the Arctic can be as thick as $20 \mathrm{~m}$ (Fig. 12), whereas the thickest ridged ice in the Southern Ocean is $16 \mathrm{~m}$ (Fig. 13). Moreover, the area taken by thick ice $(>5 \mathrm{~m})$ is much larger in the Arctic than in the Southern Ocean. Most of the simulated ice is 1-3 m thick (categories 4 and 5) in the Arctic and 1-2 $\mathrm{m}$ thick (categories 3 and 4 ) in the Southern Ocean. The open water area is small during midwinter (Figs. 12a and 13b), but increases considerably during midsummer (Figs. 12b and 13a). This is because the 1-3-m-thick (1-2 m) ice in the Arctic (the Southern Ocean) decreases quickly in the summer, so the area of open water and very thin ice $(0-0.4 \mathrm{~m})$ grows significantly. As a result, the summer ice thickness distribution generally has two peaks (in agreement 

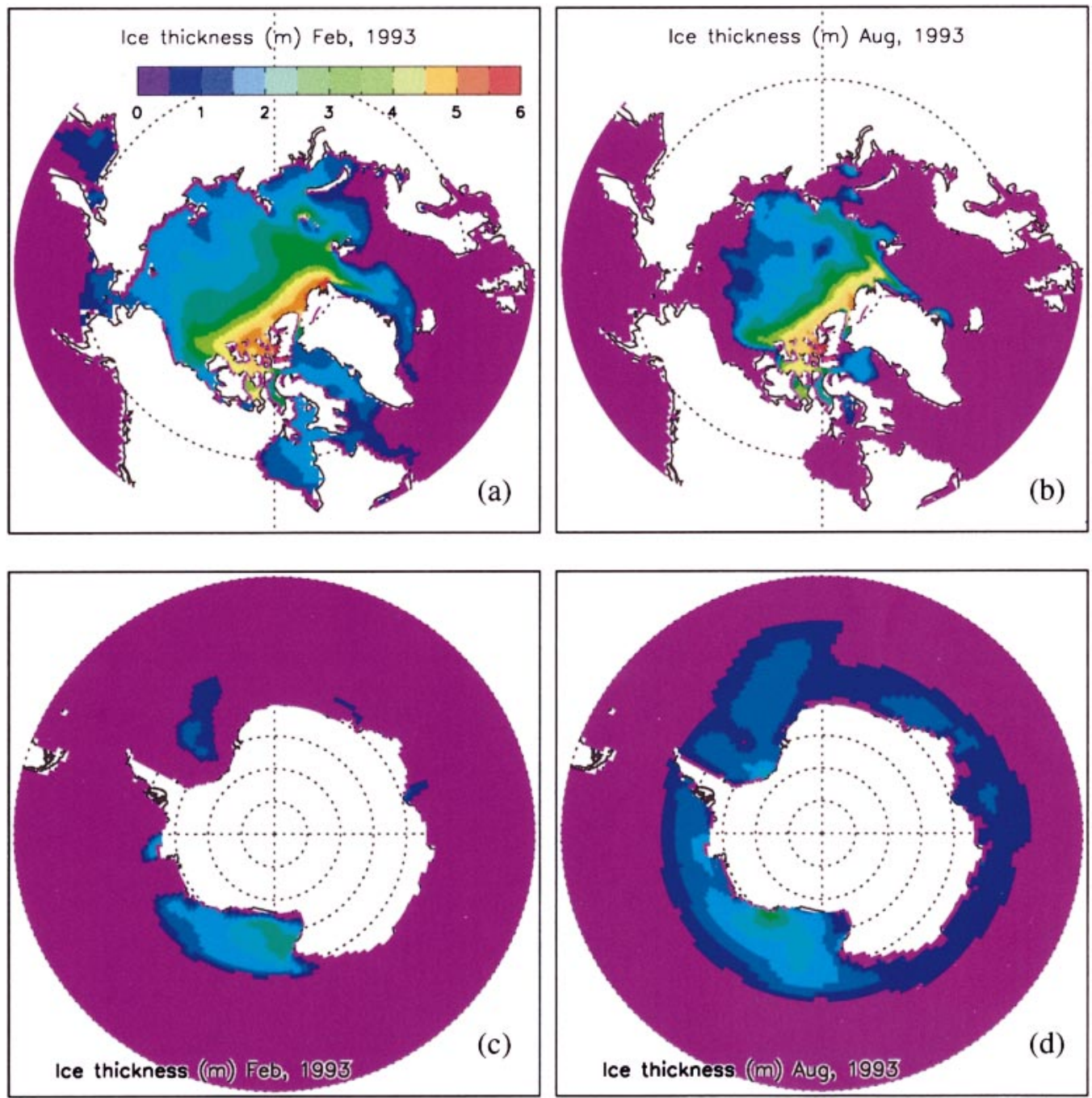

FIG. 10. Simulated mean ice thickness fields.

qualitatively with observations), one in the open-water category and the other in the 1-3 (the Arctic) or 1-2$\mathrm{m}$ (the Southern Ocean) categories.

Note finally that a sensitivity study was conducted with a different model run in which the air drag coefficient for ice was set to that of open water (section 2a), which is generally smaller than the value 0.002 adopted here and the coefficient range suggested by Overland (1985). With a smaller air drag coefficient for ice, the spatial correlation between the modeled and the observed thicknesses along the 1993 submarine track is reduced to 0.4. This indicates that realistic dynamical parameterization is important for ice thickness simulation.

\section{f. Model behavior in parallel computation}

The structure of parallel computation in the TED model follows that in the POP model (appendix B).
The POP ocean model is well behaved in parallel computation on supercomputers of parallel architecture such as the Compaq AlphaServer SC, IBM SP, and SGI Origin 2000 (see information online at http:// www.epm.ornl.gov/evaluation/PCTM). It is therefore our hope that the TED model is as well behaved as the POP model so that the parallel computation of the POIM is not severely hindered. In order to evaluate the POIM's performance in parallel computation, a series of model runs were carried out using the fully coupled POIM and a corresponding POP ocean-only model on a cluster with a varying number of $1-\mathrm{GHz}$ Athlon processors (from 1 to 10 processors). A 1-yr simulation using 10 parallel processors takes the POIM about $6 \mathrm{~h}$; approximately $3 / 5$ of which is consumed by the POP model and $2 / 5$ by the TED model.

In comparing the parallel performance of the POIM with a varying number of processors with the POP ocean-only model, the normalized computing time of 

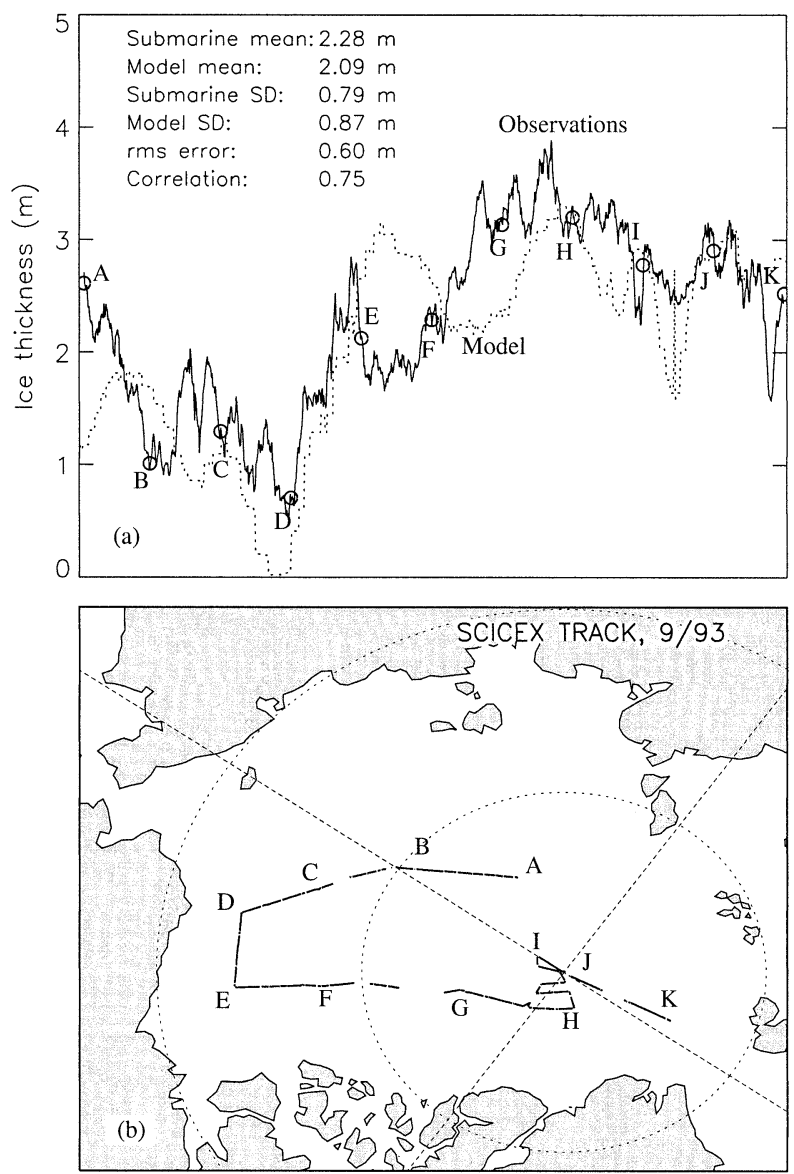

FIG. 11. Available submarine observations of ice thickness collected along the track of the submarine cruise in Sep 1993 (b); modeled (dotted line) and submarine observed (solid line) ice thicknesses along the track (a). The circles in (a) and the associated uppercase letters in (a) and (b) are marked for analyzing the results. Listed in (a) are statistical values of the modeled and observed ice thicknesses with SD representing standard deviation.

both models dropped rapidly when they were run on one to six processors, which indicates a reasonably good parallel performance (Fig. 14). However, further increasing the number of processors does not significantly reduce the computing time of either model. This, we believe, can be attributed to our cluster system. Beowulf computing software is used to control the parallel computing on the cluster with 10 processors, each of which is equipped with a $100 \mathrm{MB} \mathrm{s}^{-1}$ Ethernet card. Message exchange between the processors through the software and Ethernet cards is likely to reach a saturation point, which limits the computational efficiency, when more processors are involved. Nevertheless, when run on a small number of processors $(\sim 10)$, the parallel performance of the POIM is close to that of the POP ocean only model, which is known to have good parallel performance on high-performance parallel computers.

Although it is encouraging to note that the parallel performance of both the POIM and the POP ocean-only model are comparable with our particular cluster system,

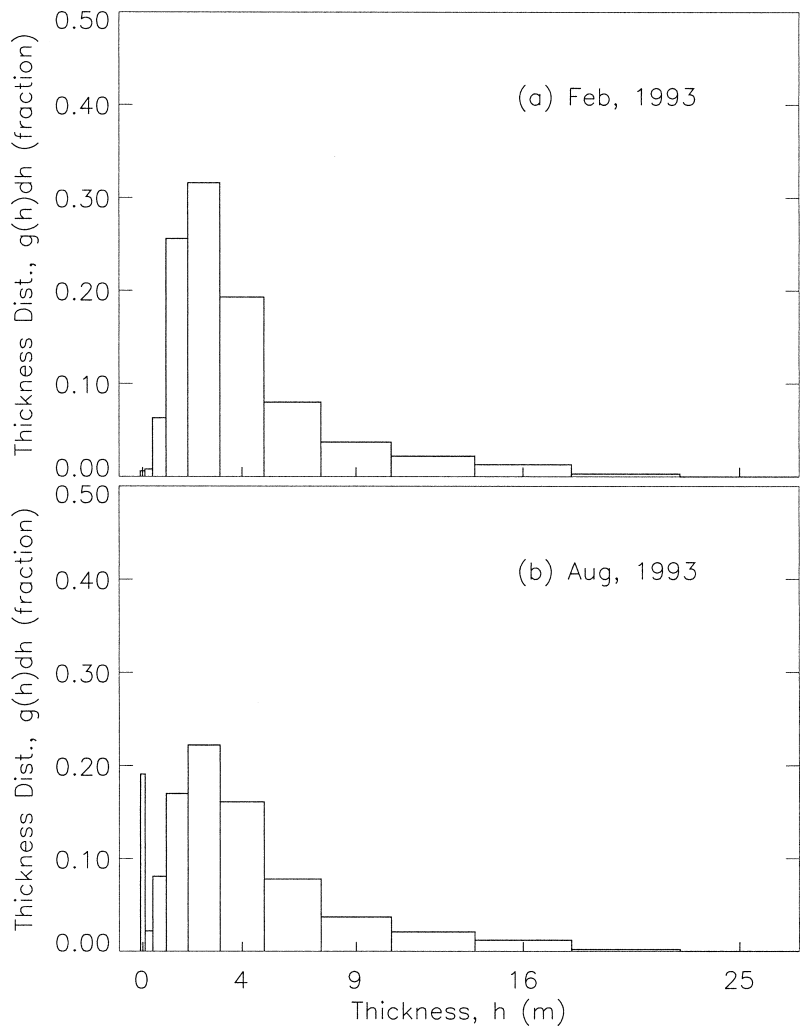

FIG. 12. Simulated mean ice thickness distribution averaged over the area north of $80^{\circ} \mathrm{N}$. The histograms are plotted over 12 bins corresponding, respectively, to the 12 ice thickness categories. They are plotted as distributions so that the area within a chosen bin represents the ice volume per unit area in the corresponding thickness interval.

we do not know whether their performance is comparable with other parallel systems, particularly in massively parallel systems. Therefore it would be useful to test the POIM further on modern supercomputers with a large number of parallel processors.

\section{Concluding remarks}

A coupled POIM in a GOCC system has been developed for global climate studies of the combined ocean and sea ice system. The POIM couples a POP ocean model with a 12-category TED sea ice model and captures the basic features of upper-ocean circulation in both polar regions. The focus of this study is on the presentation, implementation, and evaluation of the TED sea ice model in a GOCC system. The TED model is a dynamic thermodynamic model that employs a three-layer thermodynamics and a viscous-plastic rheology for ice dynamics, and simulates ice ridging. It is formulated with all the metric terms needed for a GOCC system.

Mimicking the POP's structure for parallel computation, the TED model is designed to run on a variety of computer architectures, such as parallel, serial, and 


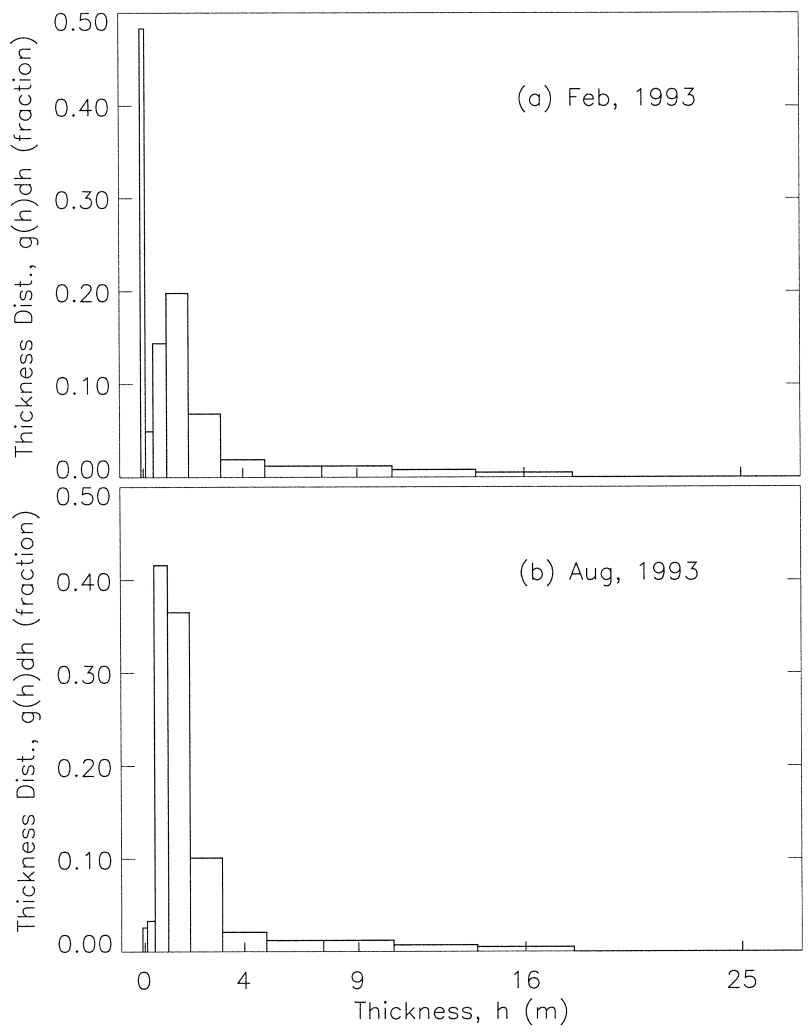

FIG. 13. Simulated mean ice thickness distribution averaged over the area south of $70^{\circ} \mathrm{S}$.

vector architectures. When run on a computer with 10 parallel processors, the parallel performance of the POIM is close to that of a corresponding POP oceanonly model. The model's calculation of the three-layer ice thermodynamics and ice mass redistribution due to the ridging process are readily adapted to parallel computation. The model's calculation of ice dynamics employing a viscous-plastic rheology and an LSR iterative solver can be easily adapted to parallel computation as well. The POIM's performance in parallel computation on modern supercomputers with massive parallel processors should be tested.

In order to evaluate the POIM's performance in modeling global sea ice, we have implemented the model on a global GOCC model grid with an average $\left\langle 4 / 5^{\circ}\right\rangle$ resolution. The POIM has been integrated over a $10-\mathrm{yr}$ period, driven repeatedly by 1993 NCEP-NCAR reanalysis surface forcing. The model results show that the POIM captures the major features of sea ice motion, concentration, extent, and thickness in both polar oceans. The results are in reasonable agreement with observations of Arctic buoy drift, satellite ice concentration, and submarine ice thickness. In particular, the model captures $56 \%$ of the variance of ice thickness along the 1993 submarine track. In a sensitivity model run using a smaller air drag coefficient for ice, the agreement between the model-simulated and submarine-ob-

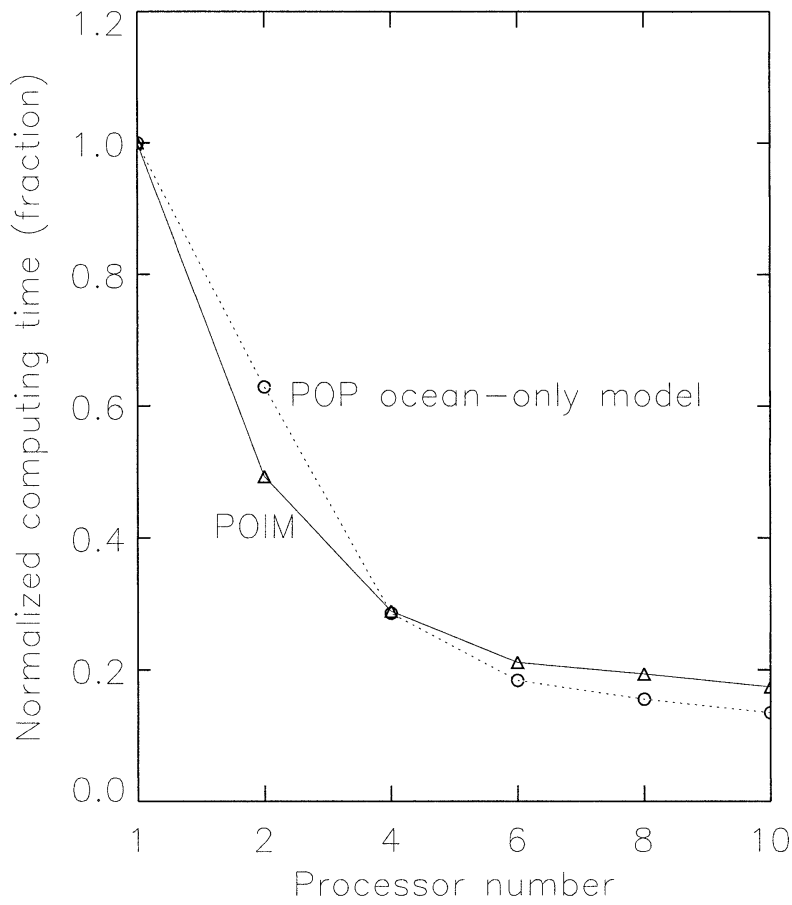

FIG. 14. Parallel performance of the POIM and the corresponding POP ocean-only model on a cluster of ten $1-\mathrm{GHz}$ Athlon processors. The computing time for each model is normalized by the model's computing time with one processor.

served ice thicknesses is reduced, indicating the importance of ice dynamics in realistically simulating ice thickness.

Although very rare, the thickest ridged ice simulated by the model is $20 \mathrm{~m}$ in the Arctic and $16 \mathrm{~m}$ in the Southern Ocean. Most of the simulated ice is 1-3 m thick in the Arctic and 1-2 $\mathrm{m}$ thick in the Southern Ocean. Summer ice thickness distribution consists of two peaks: one in the open-water category and the other in the 1-3-m-thickness categories in the Arctic and 12-m categories in the Southern Ocean.

It is through lateral advection and vertical convection that the model creates particularly large oceanic heat flux in the Odden ice area in the Greenland Sea, which often results in a tongue-shaped ice concentration in that area. The model also creates large oceanic heat flux in the Atlantic-Indian sector of the Southern Ocean where a polynya is often observed. Although the model (polynya) does not agree with the observations (no polynya) for 1993, it indicates that it is an area where the oceanic heating due to convective mixing can readily exceed the atmospheric cooling at the surface in midwinter, thus forming a polynya.

Acknowledgments. This work was supported by NASA Grant NAG5-4375 (for an EOS Interdisciplinary Investigation, Polar Exchange at the Sea Surface) and Grant NAG5-9334 (for an EOS Interdisciplinary Investigation, The Role of Polar Oceans in Contemporary 
Climate Change). Additional funding was provided by NSF Grant ATM-9905846. We thank B. Dushaw, A. Schweiger, and M. Ortmeyer for assistance in parallel computing; D. Morison for working on the model configuration in a GOCC system; B. Briegleb and R. Moritz for helpful discussions; D. Holland for providing the global bathymetry data; and Y. Yu for providing the submarine ice thickness data.

\section{APPENDIX A}

\section{Derivation of Physical Components in Generalized Orthogonal Curvilinear Coordinates}

Formulas for horizontal operators (gradient, divergence, and curl) can be found in standard textbooks. Here sea ice is described in a two-dimensional orthogonal curvilinear coordinate system. We derive the twodimensional physical components of the operators of tensors and vectors in (1)-(9) based on Malvern (1969). In indicial notation, we denote $q_{1}$ and $q_{2}$ as the two curvilinear coordinates. We also denote $h_{1}, h_{2}$ as functions of positions such that at any point in the twodimensional space, the infinitesimal element of arc length $d s$ on an arbitrary curve through that point is given by

$$
d s=d x_{1}^{2}+d x_{2}^{2}=\left(h_{1} d q_{1}\right)^{2}+\left(h_{2} d q_{1}\right)^{2},
$$

where $d x_{i}=h_{i} d q_{i}$.

\section{a. Divergence of ice velocity weighted by a scalar quantity}

From Eq. (II.2.12) in Malvern (1969) and the above relationship between $d x_{i}$ and $d q_{i}$, the second term in (5) can be written as

$$
\begin{aligned}
\boldsymbol{\nabla} \cdot(g \mathbf{u}) & =\sum_{i=1}^{2} \frac{1}{h_{i}} \frac{\partial g u_{i}}{\partial q_{i}}+\sum_{i=1}^{2}\left(\sum_{j}^{j \neq i} \frac{g u_{j}}{h_{j} h_{i}} \frac{\partial h_{i}}{\partial q_{j}}\right) \\
& =\frac{\partial g u_{1}}{\partial x_{1}}+\frac{\partial g u_{2}}{\partial x_{2}}+k_{1} g u_{1}+k_{2} g u_{2},
\end{aligned}
$$

where $k_{1}=\left(1 / h_{2}\right) \partial h_{2} / \partial x_{1}$ and $k_{2}=\left(1 / h_{1}\right) \partial h_{1} / \partial x_{2}$. The second term in (7) or (9) can be determined by replacing $g$ in (A2) with $e$ or $h g_{s}$.

\section{b. Ice interaction force}

The ice interaction force $\mathbf{F}$ is determined by the divergence of ice internal stress tensor $\sigma$, which is related to ice strain rate tensor $\dot{\varepsilon}$ and ice strength $P^{*}$ by the viscous-plastic constitutive law described in (3). The second-order tensor of strain rate is defined as

$$
\dot{\varepsilon}=\left[\begin{array}{ll}
\dot{\varepsilon}_{11} & \dot{\varepsilon}_{12} \\
\dot{\varepsilon}_{21} & \dot{\varepsilon}_{22}
\end{array}\right] \text {. }
$$

The components can be written as

$$
\begin{aligned}
\dot{\varepsilon}_{11} & =\frac{1}{h_{1}} \frac{\partial u_{1}}{\partial q_{1}}+\frac{u_{2}}{h_{1} h_{2}} \frac{\partial h_{1}}{\partial q_{2}}=\frac{\partial u_{1}}{\partial x_{1}}+k_{2} u_{2} \\
\dot{\varepsilon}_{12} & =\dot{\varepsilon}_{21} \\
& =\frac{1}{2}\left[\frac{1}{h_{2}} \frac{\partial u_{1}}{\partial q_{2}}+\frac{1}{h_{1}} \frac{\partial u_{2}}{\partial q_{1}}-\frac{1}{h_{1} h_{2}}\left(u_{1} \frac{\partial h_{1}}{\partial q_{2}}+u_{2} \frac{\partial h_{2}}{\partial q_{1}}\right)\right] \\
& =\frac{1}{2}\left[\frac{\partial u_{1}}{\partial x_{2}}+\frac{\partial u_{2}}{\partial x_{1}}-\left(k_{2} u_{1}+k_{1} u_{2}\right)\right]
\end{aligned}
$$

and, by cyclic permutation on (A3),

$$
\dot{\varepsilon}_{22}=\frac{\partial u_{2}}{\partial x_{2}}+k_{1} u_{1}
$$

The second-order tensor of ice stress is defined as

$$
\sigma=\left[\begin{array}{ll}
\sigma_{11} & \sigma_{12} \\
\sigma_{21} & \sigma_{22}
\end{array}\right]
$$

The components of the divergence of the stress tensor can be written as

$$
(\boldsymbol{\nabla} \cdot \sigma)_{1}=\frac{1}{h_{1} h_{2}}\left[\frac{\partial\left(h_{2} \sigma_{11}\right)}{\partial q_{1}}+\frac{\partial\left(h_{1} \sigma_{21}\right)}{\partial q_{2}}+\sigma_{12} \frac{\partial h_{1}}{\partial q_{2}}-\sigma_{22} \frac{\partial h_{2}}{\partial q_{1}}\right]=\frac{\partial \sigma_{11}}{\partial x_{1}}+\frac{\partial \sigma_{21}}{\partial x_{2}}+k_{1} \sigma_{11}+2 k_{2} \sigma_{21}-k_{2} \sigma_{22}
$$

and, by cyclic permutation,

$$
(\boldsymbol{\nabla} \cdot \sigma)_{2}=\frac{1}{h_{2} h_{1}}\left[\frac{\partial\left(h_{1} \sigma_{22}\right)}{\partial q_{2}}+\frac{\partial\left(h_{2} \sigma_{12}\right)}{\partial q_{1}}+\sigma_{21} \frac{\partial h_{2}}{\partial q_{1}}-\sigma_{11} \frac{\partial h_{1}}{\partial q_{2}}\right]=\frac{\partial \sigma_{22}}{\partial x_{2}}+\frac{\partial \sigma_{12}}{\partial x_{1}}+k_{2} \sigma_{22}+2 k_{1} \sigma_{12}-k_{1} \sigma_{11}
$$

given that $\sigma_{12}=\sigma_{21}$. Applying (3) and (A3)-(A5) in (A6) and (A7) gives 


$$
\begin{aligned}
F_{1}=(\nabla \cdot \sigma)_{1}= & \frac{\partial}{\partial x_{1}}(\zeta+\eta) \frac{\partial u_{1}}{\partial x_{1}}+\frac{\partial}{\partial x_{2}} \eta \frac{\partial u_{1}}{\partial x_{2}}+u_{1} \frac{\partial}{\partial x_{1}} k_{1}(\zeta-\eta)+k_{1}(\zeta+\eta) \frac{\partial u_{1}}{\partial x_{1}}+k_{2} \eta \frac{\partial u_{1}}{\partial x_{2}}-u_{1} \frac{\partial}{\partial x_{2}} k_{2} \eta \\
& -2\left(k_{1}^{2}+k_{2}^{2}\right) \eta u_{1}+\frac{\partial}{\partial x_{1}}(\zeta-\eta) \frac{\partial u_{2}}{\partial x_{2}}+k_{2} \zeta \frac{\partial u_{2}}{\partial x_{1}}+u_{2} \frac{\partial}{\partial x_{1}} k_{2}(\zeta+\eta)-3 k_{1} \eta \frac{\partial u_{2}}{\partial x_{2}}+3 k_{2} \eta \frac{\partial u_{2}}{\partial x_{1}} \\
& +\frac{\partial}{\partial x_{2}} \eta \frac{\partial u_{2}}{\partial x_{1}}-u_{2} \frac{\partial}{\partial x_{2}} k_{1} \eta-\frac{\partial}{\partial x_{1}} \frac{P^{*}}{2}
\end{aligned}
$$

and, by cyclic permutation,

$$
\begin{aligned}
F_{2}=(\boldsymbol{\nabla} \cdot \sigma)_{2}= & \frac{\partial}{\partial x_{2}}(\zeta+\eta) \frac{\partial u_{2}}{\partial x_{2}}+\frac{\partial}{\partial x_{1}} \eta \frac{\partial u_{2}}{\partial x_{1}}+u_{2} \frac{\partial}{\partial x_{2}} k_{2}(\zeta-\eta)+k_{2}(\zeta+\eta) \frac{\partial u_{2}}{\partial x_{2}}+k_{1} \eta \frac{\partial u_{2}}{\partial x_{1}}-u_{2} \frac{\partial}{\partial x_{1}} k_{1} \eta \\
& -2\left(k_{1}^{2}+k_{2}^{2}\right) \eta u_{2}+\frac{\partial}{\partial x_{2}}(\zeta-\eta) \frac{\partial u_{1}}{\partial x_{1}}+k_{1} \zeta \frac{\partial u_{1}}{\partial x_{2}}+u_{1} \frac{\partial}{\partial x_{2}} k_{1}(\zeta+\eta)-3 k_{2} \eta \frac{\partial u_{1}}{\partial x_{1}}+3 k_{1} \eta \frac{\partial u_{1}}{\partial x_{2}} \\
& +\frac{\partial}{\partial x_{1}} \eta \frac{\partial u_{1}}{\partial x_{2}}-u_{1} \frac{\partial}{\partial x_{1}} k_{2} \eta-\frac{\partial}{\partial x_{2}} \frac{P^{*}}{2} .
\end{aligned}
$$

\section{c. Thickness and enthalpy redistribution functions}

Both ice thickness and ice enthalpy redistribution functions, $\psi$ and $\Phi$, involve the product of ice stress tensor, ice deformation rate tensor, and the reciprocal of ice strength, as described in (6) and (8). However, using the viscous-plastic rheology with an elliptical yield curve allows the product to be determined by (Hibler 1980)

$$
\begin{aligned}
\sigma_{i j} \dot{\varepsilon}_{i j} P^{*-1} & =0.5\left(\Delta-\dot{\varepsilon}_{k k}\right) \\
& =0.5\left(\Delta-\frac{\partial u_{1}}{\partial x_{1}}-\frac{\partial u_{2}}{\partial x_{2}}-k_{1} u_{1}-k_{2} u_{2}\right),
\end{aligned}
$$

which simplifies the calculation of the redistribution functions because the calculation of the stress tensor $\sigma_{i j}$ is avoided and $\Delta$ in (A10) is already calculated in (4).

Equations (A3)-(A9) are the same as derived by B. P. Briegleb (2000, personal communication) using a different method. Applying (A2)-(A10) in (1)-(9) leads to their component equations in a GOCC system.

\section{APPENDIX B}

\section{Parallel Computing of the TED Sea Ice Model}

Like the POP, the POIM is designed to be run on a variety of machine architectures, including distributedmemory parallel architectures, as well as serial or vector architectures. Based on the POP's approach, the POIM's horizontal dimensions are spread across parallel processors, while its vertical dimension is held in processor (Smith et al. 1995). For the TED model, the vertical dimension is ice depth $z$ in (7). However, the $h$ dimension (ice thickness categories) in (5)-(9) is also held in processor. In other words, the calculation of ice thermodynamics and ridging is held in processor. During run time the whole model domain is divided into many subdomains, each of which is assigned to one processor to compute. Communication between subdomains is provided through a message passing interface (MPI). For portability all communication is isolated in a small set of stencil and global reduction routines provided by the POP model. No additional stencil and global reduction routines are necessary for the TED model.

Following the same numerical procedures described by Hibler (1980), Zhang and Rothrock (2001), and Flato and Hibler (1995), the parallel computing of (5), (7), and (9) in a GOCC system is relatively easy because these equations are solved explicitly. Special attention is paid to the parallel computing of ice velocity by solving the momentum equation (1) with the nonlinear viscous-plastic rheology. The equation is solved using Zhang and Hibler's (1997) ice dynamics model. This is a semi-implicit scheme with a combination of a threelevel modified Euler time stepping, an LSR procedure, and a tridiagonal matrix solver. At each LSR iteration, each processor computes the ice velocity over its assigned subdomain and then passes messages to processors in charge of the adjacent subdomains using MPI routines. The LSR iteration stops when the maximum of the difference between the ice velocity at the latest iteration and that at the previous iteration over the whole model domain is sufficiently small. The ice velocity at the latest iteration is taken as a solution.

\section{REFERENCES}

Aagaard, K., L. K. Coachman, and E. C. Carmack, 1981: On the halocline of the Arctic Ocean. Deep-Sea Res., 28, 529-545.

Arbetter, T. E., J. A. Curry, and J. A. Maslanik, 1999: Effects of rheology and ice thickness distribution in a dynamic-thermodynamic sea ice model. J. Phys. Oceanogr., 29, 2656-2670.

Bitz, C. M., M. M. Holland, A. J. Weaver, and M. Eby, 2001: Sim- 
ulating the ice-thickness distribution in a coupled climate model. J. Geophys. Res., 106, 2441-2463.

Bourke, R. H., and A. S. McLaren, 1992: Contour mapping of Arctic Basin ice draft and roughness parameters. J. Geophys. Res., 97, 17 715-17 728 .

Bryan, K., 1969: A numerical method for the study of the circulation of the world oceans. J. Comput. Phys., 4, 347-376.

Cox, M. D., 1984: A primitive equation, three-dimensional model of the oceans. GFDL Ocean Group Tech. Rep. 1, NOAA/GFDL, $250 \mathrm{pp}$.

Drinkwater, M. R., and X. Liu, 1999: Active and passive microwave determination of the circulation and characteristics of Weddell and Ross Sea ice. Proc. IGARSS' 99, Vol. 1, Hamburg, Germany, IEEE 99CH36293, 314-316.

Dukowicz, J. K., and R. D. Smith, 1994: Implicit free-surface method for the Bryan-Cox-Semtner ocean model. J. Geophys. Res., 99, 7791-8014.

Flato, G. M., and W. D. Hibler III, 1995: Ridging and strength in modeling the thickness distribution of Arctic sea ice. J. Geophys. Res., 100, 18 611-18 626.

Heil, P., and I. Allison, 1999: The pattern and variability of Antarctic sea-ice drift in the Indian Ocean and western Pacific sectors. $J$. Geophys. Res., 104, 15 789-15 802.

Hibler, W. D., III, 1979: A dynamic thermodynamic sea ice model. J. Phys. Oceanogr., 9, 815-846.

- 1980: Modeling a variable thickness sea ice cover. Mon. Wea. Rev., 108, 1943-1973.

_ , and K. Bryan, 1987: A diagnostic ice-ocean model. J. Phys. Oceanogr., 7, 987-1015.

Holland, D. M., cited 2000: Merged IBCAO/ETOPO5 global topographic data product. National Geophysical Data Center, Boulder, CO. [Available online at http://www.ngdc.noaa.gov/mgg/ bathymetry/arctic/ibcaorelatedsites.html.]

Hopkins, M. A., and W. D. Hibler III, 1991: On the ridging of a thin sheet of lead ice. Ann. Glaciol., 15, 81-86.

Kottmeier, C., and L. Sellmann, 1996: Atmospheric and oceanic forcing of Weddell Sea ice motion. J. Geophys. Res., 101, 20809 20824.

Large, W. G., and S. Pond, 1981: Open ocean momentum flux measurements in moderate to strong winds. J. Phys. Oceanogr., 11, 324-336.

Levitus, S., 1982: Climatological Atlas of the World Ocean. NOAA Prof. Paper 13, 173 pp.

Lilly, J. M., P. B. Rhines, M. Visbeck, R. Davis, J. R. N. Lazier, F. Schott, and D. Farmer, 1999: Observing deep convection in the Labrador Sea during winter 1994/95. J. Phys. Oceanogr., 29, 2065-2098.

Malvern, L. E., 1969: Introduction to the Mechanics of a Continuous Medium. Prentice Hall, 713 pp.

McPhee, M. G., and Coauthors, 1996: The Antarctic Zone Flux Experiment. Bull. Amer. Meteor. Soc., 77, 1221-1232.

Meier, W. N., and J. A. Maslanik, 1999: Assimilation of observed ice motions into a sea ice thickness distribution model, Preprints, Fifth Conf. on Polar Meteorology and Oceanography, Dallas, TX, Amer. Meteor. Soc., 486-489.

Melia, D. S., 2002: A global coupled sea ice-ocean model. Ocean Modelling, 4, 137-172.

National Center for Atmospheric Research Oceanography Section, 1996: The NCAR CSM ocean model. NCAR Tech. Note NCAR/
TN-423+STR, 75 pp. [Available from NCAR, P.O. Box 3000, Boulder, CO 80307.]

Overland, J. E., 1985: Atmospheric boundary layer structure and drag coefficients over sea ice. J. Geophys. Res., 90, 9029-9049.

Randall, D., and Coauthors, 1998: Status of and outlook for largescale modeling of atmosphere-ice-ocean interactions in the Arctic. Bull. Amer. Meteor. Soc., 79, 197-219.

Rigor, I. G., 1992: Arctic Ocean buoy program. ARGOS Newsletter, Vol. 44, No. 7, Argos Inc., 1-3.

_ gram data report for 1 January 1993-31 December 1993. APLUW TM 4-95, Applied Physics Laboratory, University of Washington, Seattle, WA, 235 pp.

Rothrock, D. A., 1975: The energetics of the plastic deformation of pack ice by ridging. J. Geophys. Res., 80, 4514-4519.

Schramm, J. L., M. M. Holland, and J. A. Curry, 1997: Modeling the thermodynamics of a sea ice thickness distribution, 1 . Sensitivity to ice thickness resolution. J. Geophys. Res., 102, 23 079-23 091.

Semtner, A. J., Jr., 1986: Finite-difference formulation of a world ocean model. Advanced Physical Oceanographic Numerical Modeling, J. O’Brien, Ed., NATO ASI Series C, Vol. 186, D. Riedel, 187-202.

Smith, R. D., J. K. Dukowicz, and R. C. Malone, 1992: Parallel ocean general circulation modeling. Physica D, 60, 38-61.

_ - S. Kortas, and B. Meltz, 1995: Curvilinear coordinates for global ocean models. LANL Rep. LA-UR-95-1146, Los Alamos National Laboratory, $53 \mathrm{pp}$

Song, X., 1994: Numerical investigation of a viscous plastic sea-ice forecasting model. M. S. thesis, Thayer School of Engineering, Dartmouth College, Hanover, NH, 108 pp.

Steele, M., and G. Flato, 2000: Sea ice growth, melt, and modeling: A survey. The Freshwater Budget of the Arctic Ocean, E. L. Lewis and E. P. Jones, Eds., Kluwer, 549-587.

Thorndike, A. S., D. A. Rothrock, G. A. Maykut, and R. Colony, 1975: The thickness distribution of sea ice. J. Geophys. Res., 80, 4501-4513.

Ushio, S., T. Takizawa, K. I. Ohshima, and T. Kawamura, 1999: Ice production and deep-water entrainment in shelf break polynya off Enderby Land, Antarctica. J. Geophys. Res., 104, $29771-$ 29780.

Wadhams, P., M. A. Lange, and S. F. Ackley, 1987: The ice thickness distribution across the Atlantic sector of the Antarctic Ocean in midwinter. J. Geophys. Res., 92, 14 535-14 552.

Winton, M., 2000: A reformulated three-layer sea ice model. J. Atmos. Oceanic Technol., 17, 525-531.

Zhang, J., and W. D. Hibler III, 1997: On an efficient numerical method for modeling sea ice dynamics. J. Geophys. Res., 102, 8691-8702.

—_, and D. A. Rothrock, 2001: A thickness and enthalpy distribution sea-ice model. J. Phys. Oceanogr., 31, 2986-3001.

_, W. D. Hibler III, M. Steele, and D. A. Rothrock, 1998a: Arctic ice-ocean modeling with and without climate restoring. J. Phys. Oceanogr., 28, 191-217.

—, D. A. Rothrock, and M. Steele, 1998b: Warming of the Arctic Ocean by a strengthened Atlantic inflow: Model results. Geophys. Res. Lett., 25, 1745-1748.

- - - and,- 2000 : Recent changes in Arctic sea ice: The interplay between ice dynamics and thermodynamics. J. Climate, 13, 3099-3114.

Zwally, H. J., J. C. Comiso, C. L. Parkinson, W. J. Campbell, F. D. Carsey, and P. Gloerson, 1983: Antarctic Sea Ice, 1973-1976 Satellite Passive-Microwave Observations. NASA, 206 pp. 